\title{
Shining Light on Sulde Perovskites: LaYS3 Material Properties and Solar Cells
}

Crovetto, Andrea; Nielsen, Rasmus; Pandey, Mohnish; Watts, Lowell; Labram, John G.; Geisler, Mathias; Stenger, Nicolas; Jacobsen, Karsten Wedel; Hansen, Ole; Seger, Brian

Total number of authors:

12

Published in:

Chemistry of Materials

Link to article, DOI:

10.1021/acs.chemmater.9b00478

Publication date:

2019

Document Version

Peer reviewed version

Link back to DTU Orbit

Citation (APA):

Crovetto, A., Nielsen, R., Pandey, M., Watts, L., Labram, J. G., Geisler, M., Stenger, N., Jacobsen, K. W. Hansen, O., Seger, B., Çhorkendorff, I., \& Vesborg, P. C. K. (2019). Shining Light on Sulde Perovskites: L̉aYS 3 Material Properties and Solar Cells. Chemistry of Materials, 31(9), 3359-3369.

https://doi.org/10.1021/acs.chemmater.9b00478

\section{General rights}

Copyright and moral rights for the publications made accessible in the public portal are retained by the authors and/or other copyright owners and it is a condition of accessing publications that users recognise and abide by the legal requirements associated with these rights.

- Users may download and print one copy of any publication from the public portal for the purpose of private study or research.

- You may not further distribute the material or use it for any profit-making activity or commercial gain

- You may freely distribute the URL identifying the publication in the public portal 


\title{
Shining light on sulfide perovskites: $\mathrm{LaYS}_{3}$ material properties and solar cells
}

Andrea Crovetto, ${ }^{*, \dagger}$ Rasmus Nielsen, ${ }^{\dagger}$ Mohnish Pandey ${ }^{\ddagger}$ Lowell Watts, ${ }^{\top}$ John G.

Labram, Mathias Geisler, ${ }^{\S} \|$ Nicolas Stenger, ${ }^{\S} \|$ Karsten W. Jacobsen, ${ }^{\ddagger}$ Ole

Hansen, ${ }^{\perp}$ Brian Seger ${ }^{\dagger} \mathrm{Ib}^{\mathrm{b}}$ Chorkendorff, ${ }^{\dagger}$ and Peter C. K. Vesborg*, ${ }^{*}$

$\dagger$ †urfCat, DTU Physics, Technical University of Denmark, DK-2800 Kgs. Lyngby,

Denmark

$\ddagger C A M D$, DTU Physics, Technical University of Denmark, DK-2800 Kgs. Lyngby, Denmark

ISchool of Electrical Engineering and Computer Science, Oregon State University, Corvallis, OR 97331, USA

$\S D T U$ Fotonik, Technical University of Denmark, DK-2800 Kgs. Lyngby, Denmark \|Center for Nanostructured Graphene (CNG), Technical University of Denmark, DK-2800

Kongens Lyngby, Denmark

$\perp$ DTU Nanotech, Technical University of Denmark, DK-2800 Kgs. Lyngby, Denmark

E-mail: crovetto.andrea@gmail.com; Peter.Vesborg@fysik.dtu.dk

\begin{abstract}
The sulfide perovskite $\mathrm{LaYS}_{3}$ has been recently identified as a promising wide band gap photoabsorber material by computational screening techniques. In this study, we combine experiment and theory to comprehensively characterize $\mathrm{LaYS}_{3}$ thin films produced by sulfurization of sputter-deposited precursors. An attractive feature of $\mathrm{LaYS}_{3}$ is its optimal band gap $(2.0 \mathrm{eV})$ for application as a wide-band gap photoabsorber in
\end{abstract}


tandem solar energy conversion devices. Promisingly, the $\mathrm{LaYS}_{3}$ films are photoconductive, with a grain size in excess of $1 \mu \mathrm{m}$ and comparable recombination timescales to state-of-the-art hybrid halide perovskite absorbers. Although the fabrication of solar cells based on $\mathrm{LaYS}_{3}$ absorbers is complicated by the high temperature necessary to grow the compound, complete solar cells could be produced in this work by growing $\mathrm{LaYS}_{3}$ on refractory metal back contacts. These are the first reported solar cells based on a sulfide perovskite absorber. A major reason for their poor performance could be the highly localized trap states observed directly by photoluminescence imaging of $\mathrm{LaYS}_{3}$, which may also explain the surprisingly long carrier lifetimes and the low carrier mobility found in this material.

\section{Keywords}

perovskite, chalcogenide, solar cells, water splitting, computational screening

\section{Introduction}

The increasingly predictive ability of computational materials science has made it possible to identify promising materials for various applications through computational screening. ${ }^{1,2}$ In particular, recent progress in the accuracy/computational effort trade-off for calculating semiconductor band gaps by density functional theory (DFT) ${ }^{3,4}$ has opened the path to screening large sets of materials for applications where the threshold energy for light absorption in the material is a crucial design parameter, such as photovoltaic- and photoelectrochemical cells for sustainable production of electricity and fuel. ${ }^{1,2,5}$

With a single material (silicon) dominating the solar cell market with over $90 \%$ market share and having reached about $90 \%$ of its maximum theoretical power conversion efficiency, ${ }^{7}$ future progress in the field will rely on coupling silicon with a wider band gap (1.6-2.0 eV) semiconductor in a single device allowing for two photoabsorber materials - the tandem cell 


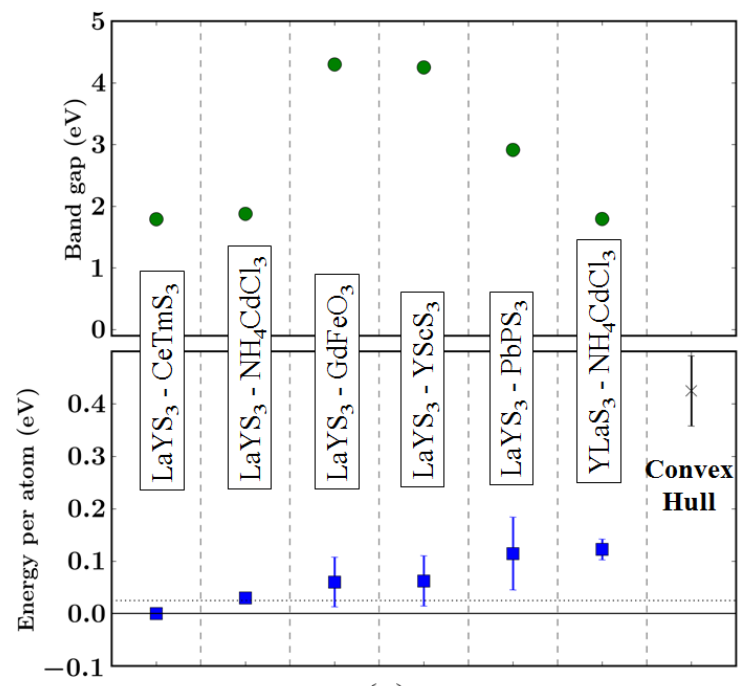

(a)
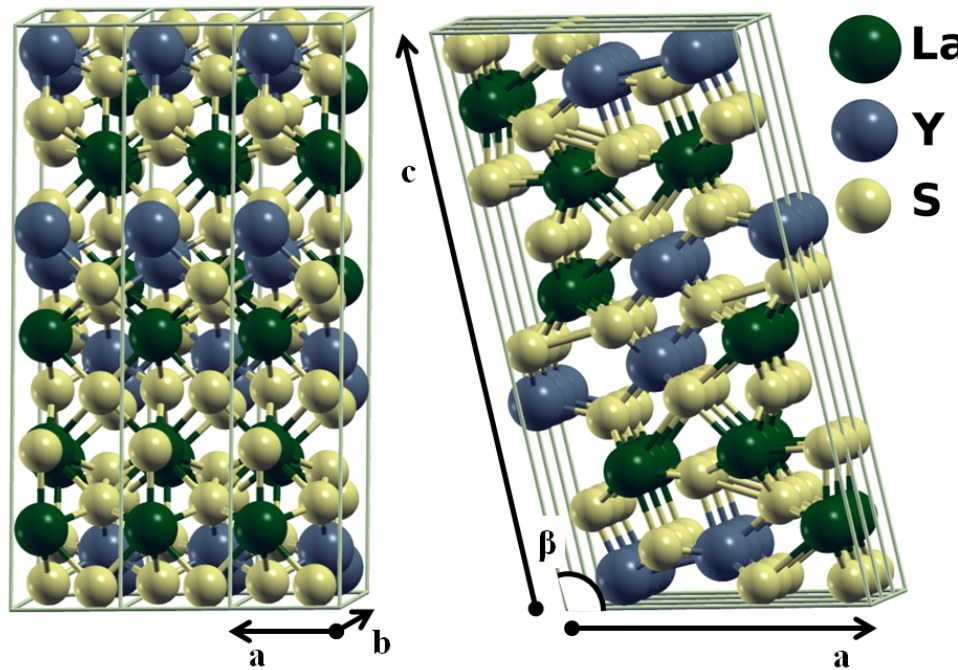

(b)

Figure 1: (a): Energy per atom, derived from the calculated heat of formation (bottom plot) and calculated band gaps (top plot) of the six lowest-energy crystal structures of $\mathrm{LaYS}_{3}$ and $\mathrm{YLaS}_{3}$. The dashed line refers to the thermal energy per atom $k_{\mathrm{B}} T$ at room temperature. As $k_{\mathrm{B}} T \simeq 0.1 \mathrm{eV}$ at the synthesis temperature of $1000^{\circ} \mathrm{C}$, all six structures may coexist, in principle. The convex Hull energy is the energy of a mix of separated $\mathrm{La}_{2} \mathrm{~S}_{3}$ and $\mathrm{Y}_{2} \mathrm{~S}_{3}$ binaries in 1:1 molar ratio. Formation of $\mathrm{LaYS}_{3}$ is therefore theoretically favored over formation of a $\left(\mathrm{La}_{2} \mathrm{~S}_{3}+\mathrm{Y}_{2} \mathrm{~S}_{3}\right)$ mixture. The energies and their error bars are calculated relative to the $\mathrm{CeTmS}_{3}$-like structure. (b): Visualization of three adjacent unit cells of $\mathrm{LaYS}_{3}$ in the monoclinic $\mathrm{CeTmS}_{3}$-like structure, where $|\mathbf{a}| \neq|\mathbf{b}| \neq|\mathbf{c}|$ and $\beta \neq 90^{\circ}$. The $\mathrm{Y}$ atoms (blue) are enclosed within corner-sharing octahedra consisting of S atoms (yellow). Y and La atoms (green) form ribbons parallel to the $\mathbf{b}$ axis. The S-Y-S bond angles are not equal to, $90^{\circ}$, implying that the octahedra are not axisymmetric (Fig. S3, Supporting Information). The other calculated $\mathrm{LaYS}_{3}$ structures are visualized elsewhere. ${ }^{6}$ Figure adapted from Ref. 6.

architecture. ${ }^{8}$ Compared to the conventional single-photoabsorber architecture, the tandem architecture significantly increases the efficiency limit for solar-to-electricity conversion and especially for electrochemical solar-to-hydrogen conversion. ${ }^{9,10}$ Even though remarkably efficient tandem solar cells and tandem water splitting cells have already been demonstrated using III-V semiconductor absorbers, ${ }^{11,12}$ the epitaxial growth processes used for those materials are too expensive for most applications. Hybrid (organic/inorganic) halide perovskite absorbers such as $\mathrm{CH}_{3} \mathrm{NH}_{3} \mathrm{PbI}_{3}\left(\mathrm{MAPbI}_{3}\right)$ could be more economical wide band gap absorbers on top of $\mathrm{Si}^{13,14}$ but there are serious concerns about their stability. ${ }^{15,16}$ For this reason, interest in fully inorganic perovskite absorbers has grown considerably. ${ }^{16}$ Most work 
so far has focused on replacing the organic molecule of hybrid perovskites with an inorganic cation, with high photovoltaic efficiencies achieved using Cs as a replacement cation. ${ }^{17}$ However, inorganic halide perovskites remain soft, low-melting point materials with high reactivity at room temperature. ${ }^{16}$ Conversely, oxide and chalcogenide perovskites are generally expected to be more stable than their halide counterparts, as they typically have much higher melting points. ${ }^{18,19}$ Oxides have been investigated rather intensely due to the possible link between photovoltaic performance and ferroelectricity in those materials. ${ }^{20}$ Sulfide and selenide perovskites have also been considered by several computational screening studies, which have identified a number of promising compounds. ${ }^{6,21,22}$ However, only a handful of sulfide perovskites have been synthesized with the goal of experimentally investigating their potential as solar absorbers. Those include $\mathrm{BaZrS}_{3}, \mathrm{Ba}(\mathrm{Zr}, \mathrm{Ti}) \mathrm{S}_{3}, \mathrm{SrZrS}_{3}, \mathrm{CaZrS}_{3}$, and $\mathrm{SrTiS}_{3} \cdot{ }^{19,23,24}$ Existing experimental studies on sulfide perovskite photoabsorbers involve materials synthesized in powder form instead of in the more device-relevant thin film form. Furthermore, no sulfide perovskite solar cells have been reported so far.

In this study, we investigate the sulfide perovskite compound $\mathrm{LaYS}_{3}$ (Fig. 1), which has rarely been mentioned in the literature and has yet to be examined as a photoabsorber. ${ }^{25,26}$ Nevertheless, $\mathrm{LaYS}_{3}$ was recently rediscovered by computational screening techniques ${ }^{6}$ as one of the most promising wide band gap photoabsorbers among sulfide perovskites, and was synthesized from metallic precursors. Here, we grow device-relevant $\mathrm{LaYS}_{3}$ thin films by sulfurization of metallic or oxide sputtered precursor films and characterize them in detail by a wide range of techniques. We find a possible advantage in the oxide precursor route due to the much larger grain size of the resulting $\mathrm{LaYS}_{3}$ films. Finally, we perform the first fabrication attempt of a sulfide perovskite single-junction solar cell. The combination of experiment and theory applied in this study reveals both advantages and drawbacks of $\mathrm{LaYS}_{3}$ as a photoabsorber, and it helps identify the factors that are currently limiting material quality and device performance. 


\section{Results}

\section{Composition}

La and $\mathrm{Y}$ targets are co-sputtered in pure $\mathrm{Ar}$ or in a $\mathrm{Ar} / \mathrm{O}_{2}$ mixture to obtain metallic or oxide precursor films with a La/Y atomic ratio close to 1, as measured by energy-dispersive x-ray spectroscopy (EDX). As-deposited oxide precursors have a $\mathrm{LaYO}_{3}$ composition and are stable in air. As-deposited metallic precursors show no visible changes in air for a few hours up to a few days depending on their stoichiometry. Higher La/Y ratios result in faster oxidation. Residual oxygen in LaY precursors is typically $20-30 \%$ of the total atomic composition after precursor deposition. For films deposited on quartz, a considerable amount of residual oxygen remains after sulfurization up to, and including, $950^{\circ} \mathrm{C}$ sulfurization temperature (Fig. $2(\mathrm{a})$ ). At $1000^{\circ} \mathrm{C}$ and $1050^{\circ} \mathrm{C}$, the oxygen content drops but it is still detected. Interestingly, residual oxygen in films deposited on metallic back contacts is generally lower even at $900^{\circ} \mathrm{C}$ sulfurization temperatures (Fig. 2(a)) and it is below the detection limit of EDX (about $1 \%$ ) after $1000^{\circ} \mathrm{C}$ sulfurization on a highly oriented pyrolytic graphite (HOPG) substrate. A possible explanation for this discrepancy is presented later in the article. No loss of either La or $\mathrm{Y}$ is observed after sulfurization in the temperature range of this study. The $(\mathrm{La}+\mathrm{Y}) /(\mathrm{S}+\mathrm{O})$ ratio in the different samples after sulfurization is consistently between 0.6 and 0.7 both from EDX and x-ray photoemission spectroscopy (XPS), as in Fig. 2(b). This is the expected stoichiometry for $\mathrm{LaYS}_{3}$ and LaY $(\mathrm{O}, \mathrm{S})_{3}$ films. No obvious in-plane compositional inhomogeneity between adjacent crystal grains is observed in EDX maps (Fig. S1, Supporting Information). Homogeneous elemental composition is also measured across the film thickness by XPS sputter depth profiling (Fig. 2(b)). The shape and binding energy of the XPS core level peaks are shown in Fig. S2, Supporting Information. 


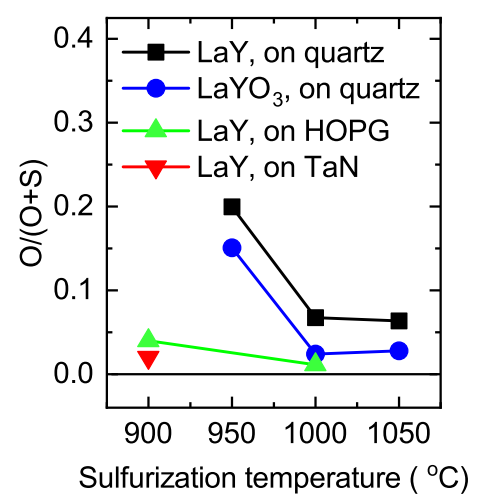

(a)

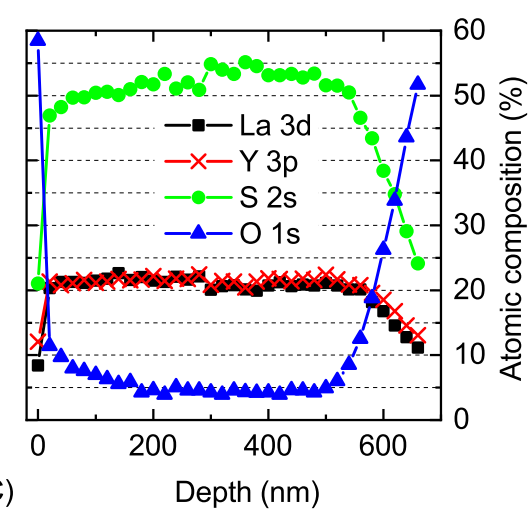

(b)

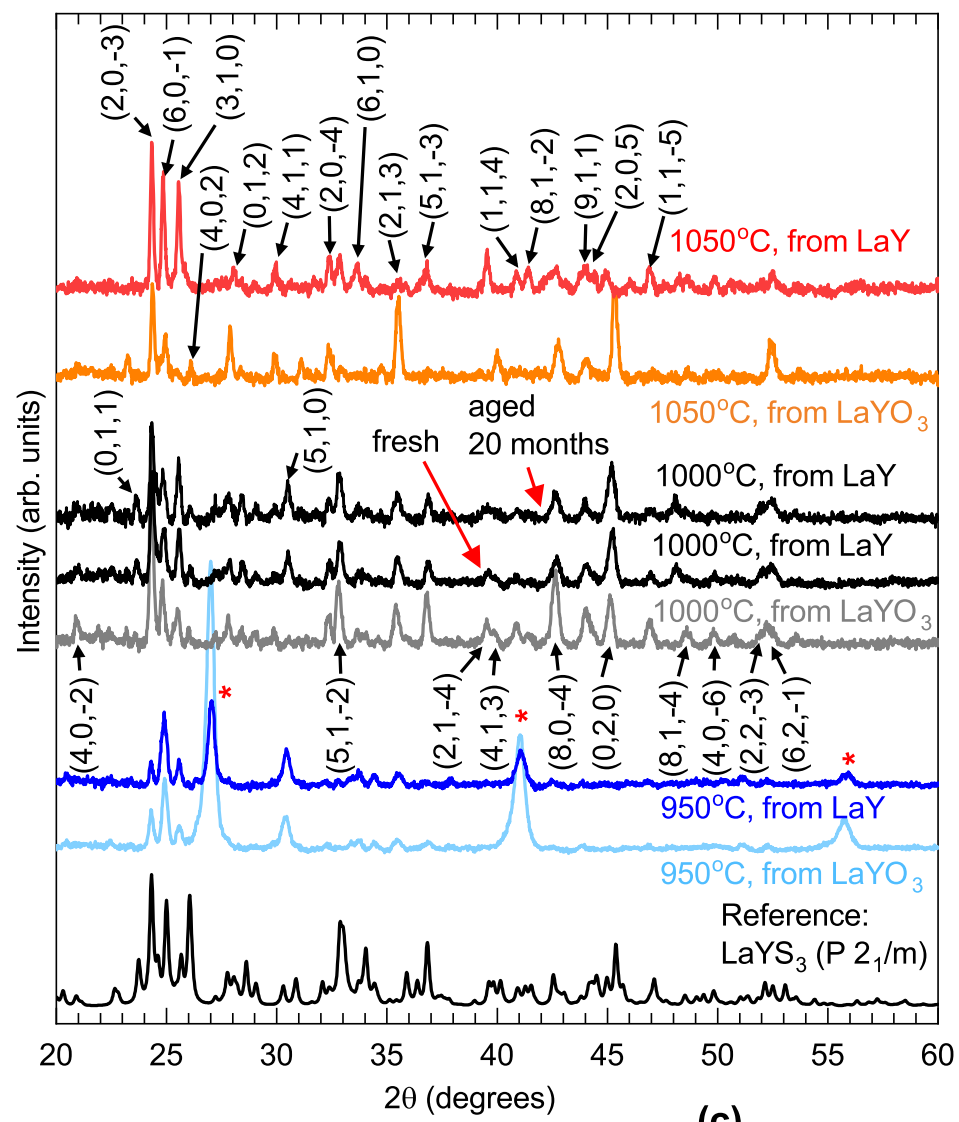

(c)

Figure 2: (a): EDX-determined atomic $\mathrm{O} /(\mathrm{O}+\mathrm{S})$ ratio in different $\mathrm{LaYS}_{3}$ films as a function of sulfurization temperature, substrate, and precursor type. (b): XPS sputter depth profile of a $\mathrm{LaYS}_{3}$ film on quartz obtained by $1000^{\circ} \mathrm{C}$ sulfurization of oxide precursors. (c): Top plots: experimental XRD pattern of (nominally) $\mathrm{LaYS}_{3}$ films on quartz sulfurized at $950^{\circ} \mathrm{C}$, $1000^{\circ} \mathrm{C}$, and $1050^{\circ} \mathrm{C}$ starting from either metal (LaY) or oxide $\left(\mathrm{LaYO}_{3}\right)$ precursors. The XRD pattern of one of the films was collected again after storing the film in ambient conditions for 20 months. The peaks marked with an asterisk are of unknown origin. (c): Bottom plot: theoretical XRD pattern of randomly oriented $\mathrm{LaYS}_{3}$ in the CeTmS 3 prototype (space group P $2_{1} / m$ ), derived from the relaxed unit cell of Fig. 1(b) with $0.2^{\circ} 2 \theta$ broadening (adapted from Ref. 6). 


\section{Structural properties}

According to the computational results shown in Fig. 1(a), the monoclinic $\mathrm{CeTmS}_{3}$ prototype (space group P $2_{1} / m$ ) is the thermodynamically favored crystal structure for $\mathrm{LaYS}_{3}$. This is also found in the only existing experimental study of a $\mathrm{LaYS}_{3}$ powder, which was found to crystallize in the $\mathrm{CeTmS}_{3}$-like structure (collection code 641874 in the Inorganic Crystal Structure Database, ICSD). ${ }^{25}$ Fig. 1(b) depicts the 40 -atom unit cell of the $\mathrm{LaYS}_{3}$-CeTmS 3 structure, in which the $\mathrm{Y}$ atoms are located inside nonaxisymmetric corner-sharing octahedra made up of S atoms (Fig. S3, Supporting Information). The $\mathbf{a}, \mathbf{b}$, and $\mathbf{c}$ axis lengths and the $\beta$ angle in the relaxed unit cell are calculated as $11.07 \AA, 3.99 \AA, 21.49 \AA$, and $102.32^{\circ}$ respectively. This is within less than $1 \%$ of the experimentally determined values for a $\mathrm{LaYS}_{3}$ powder (11.09 $\AA, 3.98 \AA, 21.36 \AA$, and $102.74^{\circ}$ respectively). ${ }^{25}$ According to the empirical Goldschmidt rule for structure prediction of perovskite materials, $\mathrm{LaYS}_{3}$ is indeed expected to crystallize in a low-symmetry structure due to its low tolerance factor of $0.74,{ }^{27}$ even though the specific $\mathrm{CeTmS}_{3}$-like crystal structure is not considered in the Goldschmidt rule. The energy and band gaps of all the calculated $\mathrm{LaYS}_{3}$ and $\mathrm{YLaS}_{3}$ structures (17) are shown in Fig. S4, Supporting Information.

In our previous work, $\mathrm{LaYS}_{3}$ in the $\mathrm{CeTmS}_{3}$-like crystal structure was experimentally found to be the dominant phase in a thin film obtained by sulfurizing metallic precursors at $1000^{\circ} \mathrm{C} .{ }^{6}$ Here, we observe that oxide precursors yield fairly similar x-ray diffraction (XRD) patterns to metallic precursors after sulfurization at $1000^{\circ} \mathrm{C}$ (Fig. 2(c)). Hence, it can be concluded that structurally similar films predominantly consisting of $\mathrm{LaYS}_{3}$ in the $\mathrm{CeTmS}_{3}$-like structure can be obtained from either metallic or oxide precursors. It must be emphasized, however, that the combination of a low-symmetry (monoclinic) crystal system and a large (40-atom) unit cell in the $\mathrm{CeTmS}_{3}$-like structure implies that a large number of low-intensity XRD peaks are expected for this crystal structure over wide $2 \theta$ ranges (see the theoretical XRD pattern at the bottom of Fig. 2(c)). The situation is similar for the other possible $\mathrm{LaYS}_{3}$ structures in Fig. 1(a). Their theoretical XRD patterns, together with 
reference XRD patterns of several La- and Y sulfides, oxides and oxysulfides are listed in Fig. S5, Supplementary Information. Even though the $\mathrm{CeTmS}_{3}$-like structure of $\mathrm{LaYS}_{3}$ appears as the best match to the experimental patterns of the $1000^{\circ} \mathrm{C}$-sulfurized films, the abundance of peaks expected for most reasonable competing phases makes it difficult to confidently index all experimental peaks to a certain crystal structure. Unfortunately, the applicability of complementary structural characterization techniques, such as Raman and IR spectroscopy, is limited due to the lack of reference spectra for $\mathrm{LaYS}_{3}$. To elucidate whether phase-pure $\mathrm{LaYS}_{3}$ in the $\mathrm{CeTmS}_{3}$-like structure can be produced as thin films, more detailed XRD studies of $\mathrm{LaYS}_{3}$ thin films, as well as theoretical/experimental investigation of Ramanand IR-active vibrational modes in $\mathrm{LaYS}_{3}$ are called for.

The films sulfurized at $950^{\circ} \mathrm{C}$ exhibit several strong and broad peaks (at 27.0, $41.1^{\circ}$, and $55.8^{\circ}$ ) which are absent in the samples sulfurized at higher temperatures. Especially the peaks at $27.0^{\circ}$ and $55.8^{\circ}$ cannot be indexed to the $\mathrm{CeTmS}_{3}$-like crystal structure of $\mathrm{LaYS}_{3}$ or to other possible $\mathrm{LaYS}_{3}$ structures (Fig. S5, Supporting Information). They could in principle be assigned to $\mathrm{La}_{2} \mathrm{~S}_{3}$ and $\mathrm{Y}_{2} \mathrm{~S}_{3}$ binaries, but in view of the residual oxygen found in those films (Fig. 2(a)) the broad peaks are more likely to belong to an unknown LaY $(\mathrm{O}, \mathrm{S})_{3}$ phase. Unfortunately, neither computational nor experimental structural data is available for $\mathrm{LaY}(\mathrm{O}, \mathrm{S})_{3}$ compounds. We conclude that a sulfurization temperature of $950^{\circ} \mathrm{C}$ is not sufficient as it results in a multi-phase film.

The films sulfurized at $1050^{\circ} \mathrm{C}$ have somewhat narrower peaks (larger crystallite size) compared to the case of $1000^{\circ} \mathrm{C}$ sulfurization. However, the XRD pattern is more dependent on the type of precursor used, with the peaks at $27.9^{\circ}, 35.5^{\circ}, 45.3^{\circ}$, and $52.4^{\circ}$ being much more intense in the film obtained from oxide precursors. Furthermore, a higher sulfurization temperature makes it even more challenging to incorporate $\mathrm{LaYS}_{3}$ into a device. For this reason, the rest of the characterization results presented in this article refer to films obtained by $1000^{\circ} \mathrm{C}$ sulfurization, unless otherwise specified. The $\mathrm{LaYS}_{3}$ films are structurally stable in ambient air at room temperature within a time frame of months/years, as can be seen by 


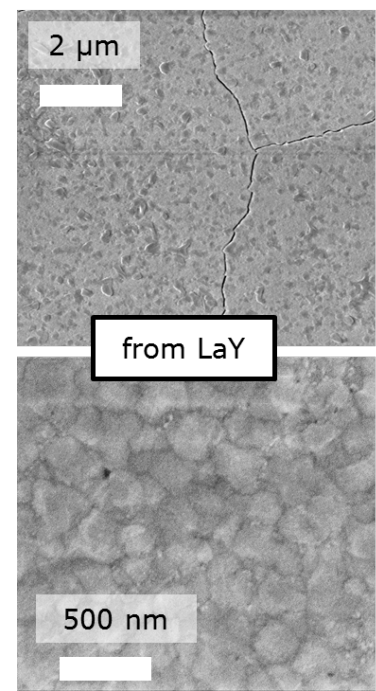

(a)

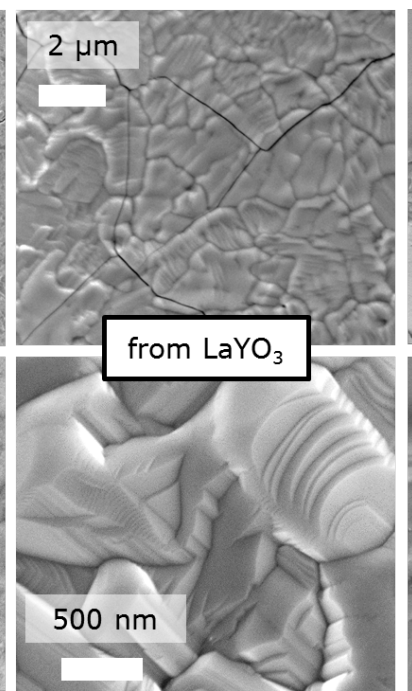

(b)

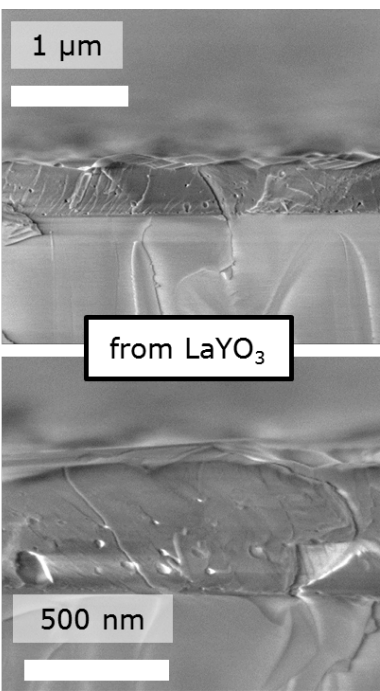

(c)

Figure 3: (a, b): Top-view SEM images of $\mathrm{LaYS}_{3}$ film obtained from (a) metallic LaY precursors and (b) oxide $\mathrm{LaYO}_{3}$ precursors. (c): Cross-sectional SEM images of $\mathrm{LaYS}_{3}$ film obtained from oxide precursors. Top (bottom) row: low (high) magnification images.

comparing two XRD patterns collected on the same sample immediately after synthesis and after 20 months of air exposure (Fig. 2(c)).

\section{Morphology}

$\mathrm{LaYS}_{3}$ films obtained from metallic and oxide precursors and sulfurized simultaneously at $1000^{\circ} \mathrm{C}$ are markedly different in morphology, as shown in Fig. 3. Metallic precursors yield smoother $\mathrm{LaYS}_{3}$ films with small grains in the 100-200 nm diameter range. Oxide precursors result in much larger grains (1-2 $\mu$ m diameter) with higher average surface roughness but often exhibiting very smooth facets (Fig. 3). Cross-sectional scanning electron microsocope (SEM) images on $\mathrm{LaYS}_{3}$ films obtained from oxide precursors reveal that the grains extend throughout the film thickness, with good adhesion to the quartz substrate. However, small voids (tens of nm size) exist in the bulk of the film. Cracks across the whole film thickness are also seen in cross sectional images and in low-magnification top-view images (Fig. S6, Supporting Information). They are probably due to the mismatch in thermal expansion coefficient between $\mathrm{LaYS}_{3}$ and $\mathrm{SiO}_{2}$, which is exacerbated by the very high process temper- 
ature. The distance between cracks is fairly regular across a sample, and it decreases with increasing sulfurization temperature and with decreasing ramp-down time after sulfurization. Even at very slow ramp rates $\left(2^{\circ} \mathrm{C} / \mathrm{min}\right)$ we were unable to avoid cracking in the films. The film thickness measured by SEM and ellipsometry is around 500-600 $\mathrm{nm}$ for both types of precursors.

Interestingly, the combination of SEM and EDX maps on $\mathrm{LaYS}_{3}$ produced from metallic precursors show areas approximately $10 \mu \mathrm{m}$ in diameter spaced by 50-100 $\mu \mathrm{m}$ (Fig. S7, Supporting Information) that are rich in Si and O (Fig. S8, Supporting Information). Performing Raman spectroscopy on those areas reveals that they primarily consist of elemental

Si (peak at $520 \mathrm{~cm}^{-1}$ ). This may be explained by reduction of the quartz substrate from $\mathrm{SiO}_{2}$ to $\mathrm{Si}$ upon high-temperature sulfurization due to the presence of the highly reducing species $\mathrm{Y}$ and La. The small amounts of residual oxygen observed in all samples may thus originate from the quartz substrate. Elemental $\mathrm{Si}$ is more easily observed in $\mathrm{LaYS}_{3}$ films obtained from metallic precursors, so we conclude that oxide precursors are preferable both in terms of grain size and less contamination from the substrate. Therefore, the rest of the characterization results related to $\mathrm{LaYS}_{3}$ films on quartz refers to films obtained from oxide precursors, unless otherwise specified.

\section{Optical properties}

According to calculations with the GLLB-SC approach (computational details in the Supporting Information), the band gap of $\mathrm{LaYS}_{3}$ in the $\mathrm{CeTmS}_{3}$-like structure is estimated as $(1.79 \pm 0.30) \mathrm{eV}$ (Fig. 1(a)). The band gap is direct and located at the $\Gamma$ point of the Brillouin zone (Fig. 4(a)). Experimental band gaps of $\mathrm{LaYS}_{3}$ films sulfurized at $1000^{\circ} \mathrm{C}$ and $1050^{\circ} \mathrm{C}$ are consistently around $(2.0 \pm 0.1) \mathrm{eV}$ according to Tauc plots for direct band gap materials, ${ }^{6}$ roughly independent of temperature and precursor type. Their refractive index in the transparent region is between 2.4 and 2.6 according to ellipsometry (Fig. S9, Supporting Information). Although a lower sulfurization temperature would be an advantage for 


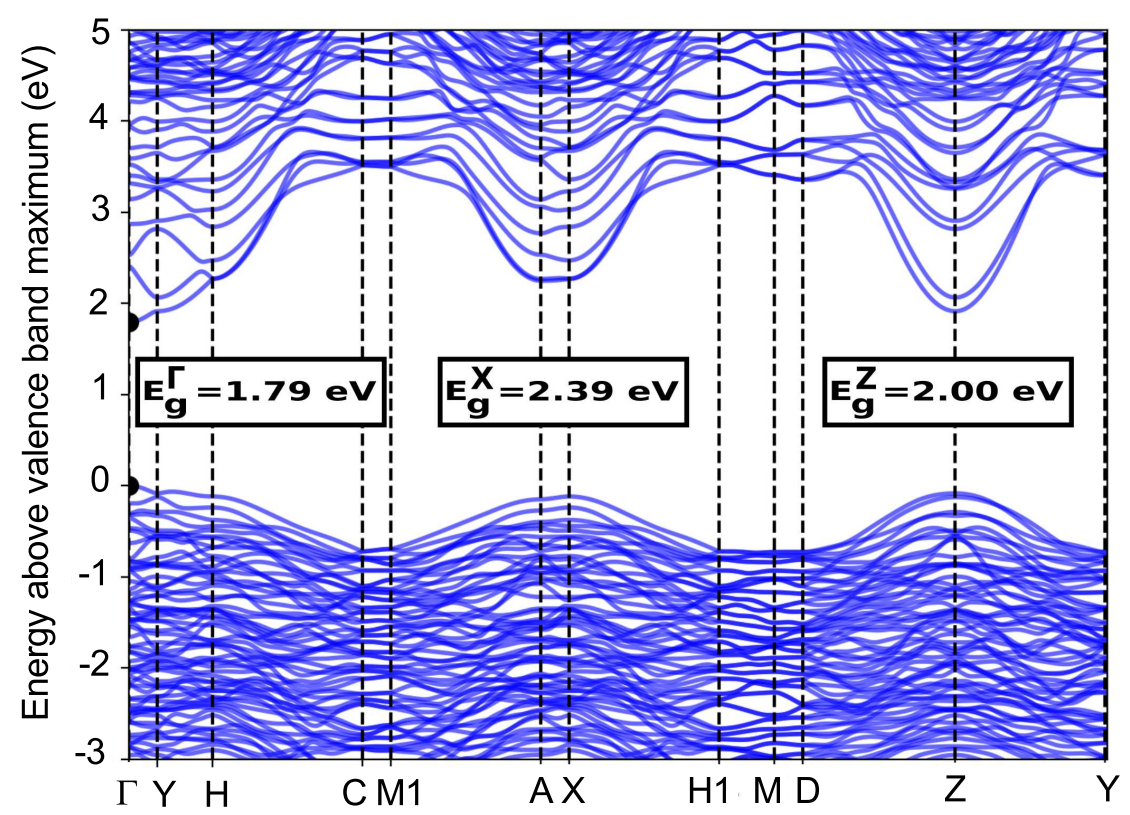

(a)

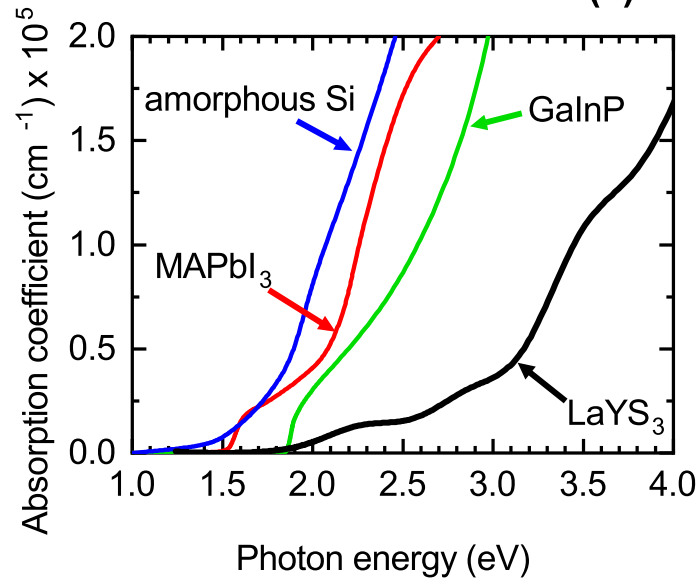

(b)

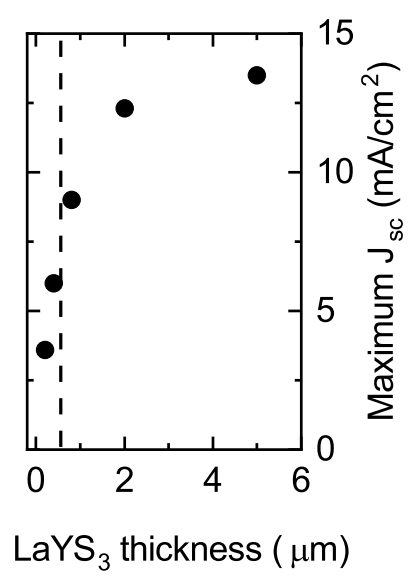

(c)

Figure 4: (a): Calculated band structure (GLLB-SC approach) of $\mathrm{LaYS}_{3}$ in the $\mathrm{CeTmS}_{3}$-like structure. Note the three direct band gaps at the $\Gamma, \mathrm{X}$, and $\mathrm{Z}$ point, which are closely spaced in energy. (b): Absorption coefficient of $\mathrm{LaYS}_{3}$ according to spectroscopic ellipsometry (adapted from Ref. 6.). Absorption coefficients of other wide band gap absorbers are shown for comparison. ${ }^{28-30}$ (c): Maximum short circuit current potentially achievable by a singlejunction $\mathrm{LaYS}_{3}$ solar cell as a function of $\mathrm{LaYS}_{3}$ thickness. The vertical dashed line indicates the thickness of the films synthesized in this study.

process integration, films sulfurized at $950^{\circ} \mathrm{C}$ or below have higher band gaps. Absorption coefficients used for Tauc analysis are derived both by optical transmission measurements and by ellipsometry measurements (Fig. 4(b)), with good agreement between the resulting band gaps (Fig. S9, Supporting Information). Importantly, a band gap of $2.0 \mathrm{eV}$ is optimal 
for application of $\mathrm{LaYS}_{3}$ as a wide band gap absorber in tandem photovoltaic cells, as well as in tandem photoelectrochemical water splitting cells. ${ }^{8-10}$ However, the absorption coefficient of $\mathrm{LaYS}_{3}$ is relatively low in the first $0.5 \mathrm{eV}$ above the band gap, in comparison with other direct band gap photoabsorbers of similar band gaps (Fig. 4(b)). This results in the dark yellow appearance of our $500 \mathrm{~nm} \mathrm{LaYS}$ films on quartz. Unfortunately, the absorption coefficient of $\mathrm{LaYS}_{3}$ could not be calculated explicitly with a high-level theoretical approach due to the large unit cell size. Nevertheless, weak absorption in the first $0.5 \mathrm{eV}$ above the band gap energy may be rationalized by examining the calculated band structure of $\mathrm{LaYS}_{3}$ in the $\mathrm{CeTmS}_{3}$-like structure (Fig. 4(a)) and using qualitative arguments. The lowest-energy optical transitions are direct transitions at the $\Gamma$ point, involving a single valence band and a single conduction band, both of which are fairly disperse (calculated hole and electron effective masses of $0.67 m_{\mathrm{e}}$ and $0.49 m_{\mathrm{e}}$ respectively). ${ }^{6}$ This implies weak absorption due to the relatively low joint density of states for those transitions. At slightly higher photon energies, though, various other optical transitions become available, in particular a direct transition at the $\mathrm{Z}$ point starting at $2.00 \mathrm{eV}$, and direct transitions at the $\mathrm{A}$ and $\mathrm{X}$ points starting at $2.39 \mathrm{eV}$. In particular, between the $\mathrm{A}$ and $\mathrm{X}$ points both the valence and the conduction band are almost parallel, which is likely to result in strong absorption.

From a device perspective, the most important consequence of a relatively weak absorption coefficient is that a thick film is necessary to achieve a high short circuit current. As shown in Fig. 4(c), large short circuit current losses are expected for film thicknesses below $2 \mu \mathrm{m}$ due to incomplete light absorption. Weak absorption also implies that a larger diffusion length is necessary to achieve the same carrier collection probability of strongly absorbing materials. This translates into more stringent requirements on minority carrier lifetime and mobility. We finally note that the band gap of $\mathrm{LaYO}_{3}$ precursors is over $5.0 \mathrm{eV}$, with refractive index between 1.7 and 1.8 in the visible region according to ellipsometry (Fig. S10, Supporting Information). 


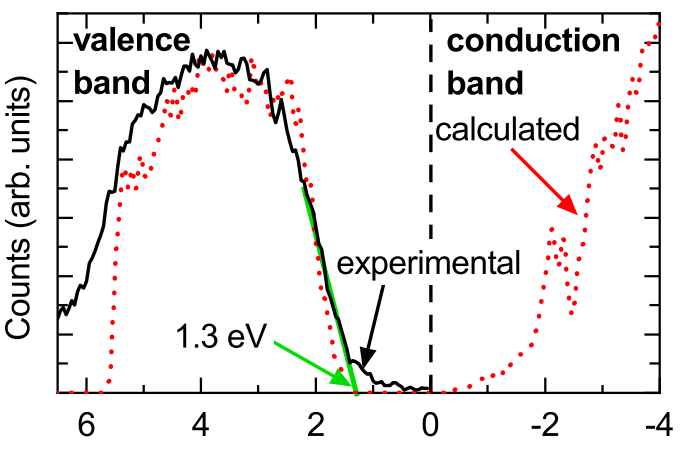

(a)

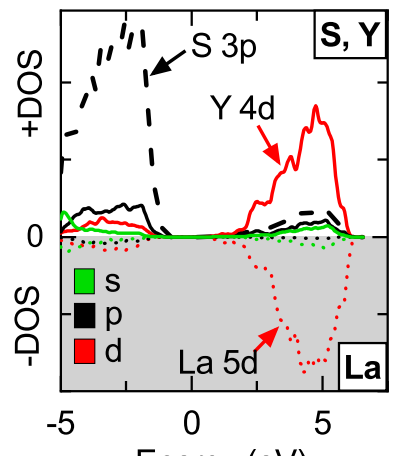

(b) Energy (eV)

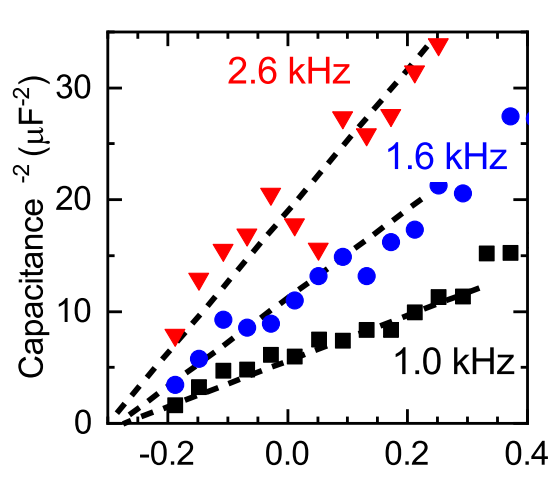

(c)

Potential vs. RHE (V)

Figure 5: (a): XPS spectrum of $\mathrm{LaYS}_{3}$ at low binding energies (black solid line). Zero binding energy corresponds to the Fermi level in the material. The photoemission onset corresponds to the topmost states of the valence band. The calculated DOS is also plotted for comparison (red dashed line). Note that the calculated DOS has been shifted in energy, since the Fermi level in the measurement and in the calculation are defined differently. (b): Orbital-resolved calculated DOS for $\mathrm{LaYS}_{3}$. The DOS from Y, La, and S orbitals are plotted with solid, short dashed, and long dashed lines respectively. The DOS from s, p, and d orbitals are plotted in green, black, and red respectively. For easier visualization, the DOS from La orbitals are shown with a reverse sign. (c): Electrochemical Mott-Schottky plot at three different frequencies, showing n-type doping and a flat-band potential of about $-0.25 \mathrm{~V}$ vs. RHE. (d): In-plane two-point resistivity measurement of a $\mathrm{LaYS}_{3}$ film on quartz in the dark and under white light illumination at $10 \mathrm{~mW} / \mathrm{cm}^{2}$ (about 0.1 suns), showing a photoconductivity effect.

\section{Electronic properties and photoconductivity}

The valence band density of states spectrum (DOS), as measured by XPS, shows good agreement with the calculated DOS (Fig. 5(a)). The additional broadening of the experimental data is compatible with XPS instrumental broadening. The higher DOS close to the valence band maximum compared to the conduction band minimum is due to the many closely 
spaced valence bands seen in the band structure (Fig. 4(a)). Projection of the total density of states onto orbitals (Fig. 5(b)) indicates that the valence band consists mostly of S 3p states, whereas the conduction band is primarily made up of $\mathrm{d}$ states from both La and Y. The experimental valence band position, estimated by extrapolating the photoemission onset of Fig. 5(a) with a straight line ${ }^{31}$ is $1.3 \mathrm{eV}$ below the Fermi level, that is, close to midgap. This suggests that $\mathrm{LaYS}_{3}$ may have weak n-type native doping. N-type conductivity is indeed confirmed by the positive slope of electrochemical Mott-Schottky plots shown in Fig. 5(b), even though the strong frequency dependence of the measured capacitance, possibly due to high series resistance, prevents reliable determination of the doping density.

Importantly for solar energy conversion applications, $\mathrm{LaYS}_{3}$ films are photoconductive, as their in-plane resistivity decreases by a factor of 5 upon illumination with white light at $10 \mathrm{~mW} / \mathrm{cm}^{2}$ (about 0.1 suns), as shown in Fig. 5(d). Note, however, that the very high in-plane resistivity measured here is an upper limit to the actual film resistivity due to the two-point measurement method employed, as well as to the presence of cracks in the film, which may force the current to flow through percolation paths in a planar measurement. More realistic estimates of the film resistivity may be given by methods probing the out-of plane resistance. Two of such methods are the evaluation of series resistance in a complete solar cell, and the evaluation of the cutoff frequency in a capacitance-frequency measurement. Both methods point to a bulk resistivity in the $10^{6} \Omega \mathrm{cm}$ range, as illustrated in Figs. S11,S12, Supporting Information. The latter method also yields a rough estimate of $7 \pm 2$ for the static relative permittivity (dielectric constant) of $\mathrm{LaYS}_{3}$. The relative permittivity of $\mathrm{LaYS}_{3}$ is, then, much smaller than the exceptionally high permittivity of $\mathrm{MaPbI}_{3}{ }^{32}$ and is more in line with that of diamond-like inorganic semiconductors of similar band gaps. ${ }^{33}$ This may imply less defect tolerance than in $\mathrm{MaPbI}_{3}$ due to less efficient screening of charged defects. ${ }^{32}$ 

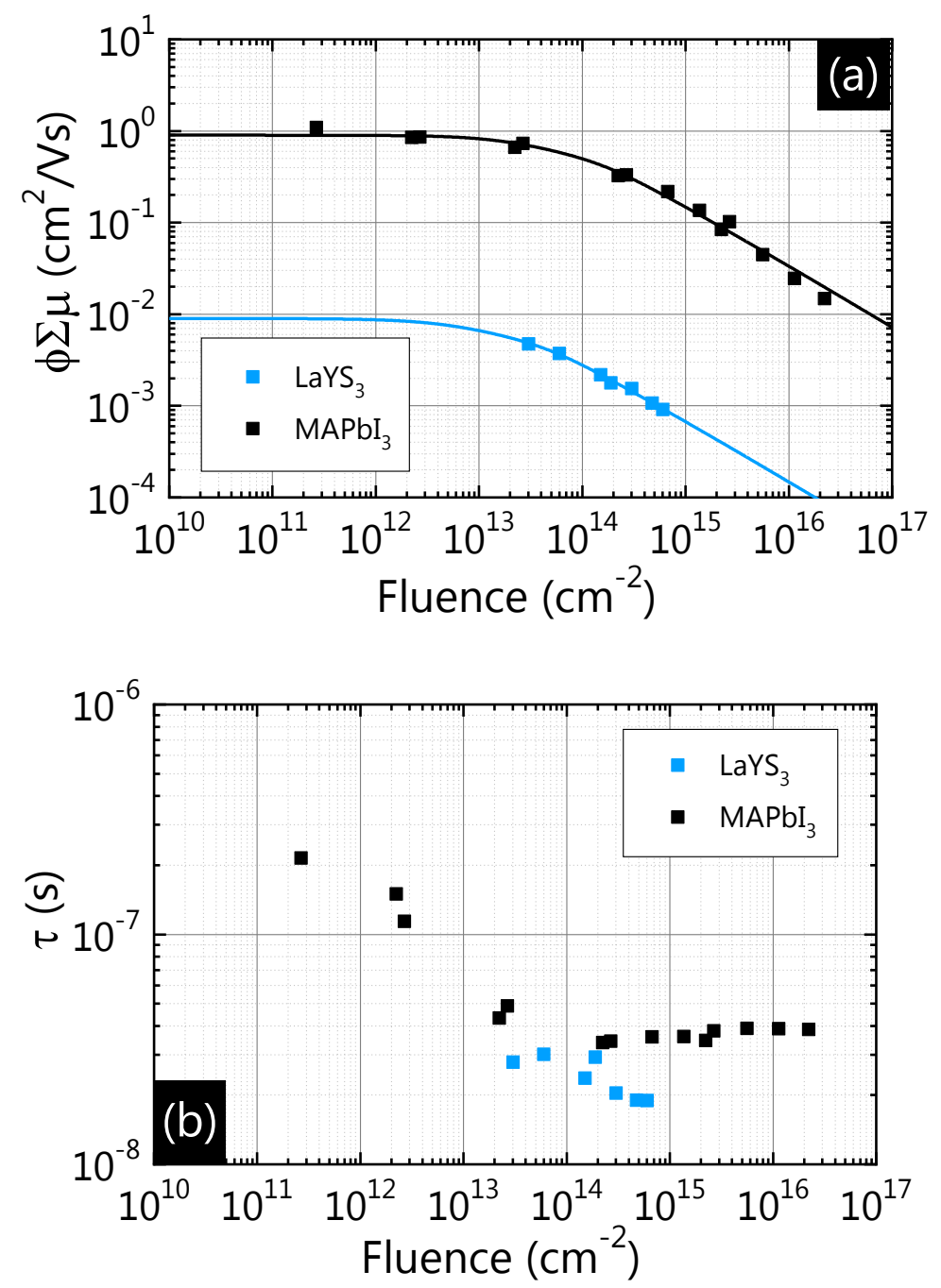

Figure 6: (a): TRMC figure of merit $\phi \sum \mu=\phi\left(\mu_{e}+\mu_{h}\right)$, plotted as a function of excitation fluence for films of $\mathrm{LaYS}_{3}$ and $\mathrm{MAPbI}_{3}$. The points are experimental data, and the lines are fits to a numerical model which accounts for bimolecular and Auger recombination at high fluence. ${ }^{34}$ From these fits we evaluate representative values of the TRMC figure of merit. (b): Approximate carrier lifetime $(\tau)$ evaluated by fitting a single exponential function to TRMC transients as a function of optical fluence for same films of $\mathrm{LaYS}_{3}$ and $\mathrm{MAPbI}_{3}$. The fluence range available for $\mathrm{LaYS}_{3}$ is limited by the lower signal-to-noise ratio compared to $\mathrm{MAPbI}_{3}$ (on the low fluence side) and by the fact that the decay time approaches the instrumental response time (on the high fluence side). Using measured values of film thickness and absorbance, the initial excess carrier density $\Delta n$ after the laser pulse (injection level) is between $2 \times 10^{16} \mathrm{~cm}^{-3}$ and $4 \times 10^{17} \mathrm{~cm}^{-3}$ for $\mathrm{LaYS}_{3}$. The corresponding $\Delta n$ for $\mathrm{MAPbI}_{3}$ is one order of magnitude higher at the same fluence, due to its much higher absorption coefficient. 


\section{Carrier lifetime, mobility, and defects}

The electronic quality of $\mathrm{LaYS}_{3}$ films is investigated by time-resolved microwave conductivity (TRMC) and photoluminescence (PL). With TRMC, it is possible to evaluate a proxy for the sum of in-plane electron and hole mobilities, as well as an estimate for the minority carrier lifetime. ${ }^{35,36}$ The TRMC figure of merit $\phi \sum \mu=\phi\left(\mu_{e}+\mu_{h}\right)$, which is proportional to the peak photo-conductance value after the laser pulse, is plotted in Fig. 6(a) for $\mathrm{LaYS}_{3}$ and for a $\mathrm{MAPbI}_{3}$ control sample as function of optical fluence. Here $\phi$ is the charge-generation efficiency, and $\mu_{e}$ and $\mu_{h}$ are the electron and hole mobilities, respectively. Thus, the parameter $\phi \sum \mu$ has the same dimensions as mobility but the individual mobility contributions from the two carrier types are not resolved. For systems with low exciton binding energy, such as $\mathrm{MAPbI}_{3}, \phi$ is very close to unity and therefore $\phi \sum \mu \approx \sum \mu=\mu_{e}+\mu_{h}$. It is likely that the latter approximation is also applicable to $\mathrm{LaYS}_{3}$ since its relative permittivity and effective masses are in line with common inorganic semiconductors. In fact, the exciton binding energy of $\mathrm{LaYS}_{3}$ is estimated to be $70 \mathrm{meV}$ with a simple hydrogen atom model, ${ }^{37}$ using the measured permittivity and calculated effective masses. Hence, we interpret $\phi \sum \mu$ as mobility. At high optical fluence, a significant amount of bimolecular and Auger recombination will occur during the $\sim 5$ ns laser pulse, resulting in a reduction in peak observable photo-conductance, and hence a reduction in extracted $\phi \sum \mu$, as observed in Fig. 6(a). This is a widely-observed phenomenon in TMRC, ${ }^{35,38}$ and models have been developed to account for it. ${ }^{34}$ By applying the model in Ref. 34, we evaluate $\phi \sum \mu=0.009 \mathrm{~cm}^{2} / \mathrm{Vs}$ for $\mathrm{LaYS}_{3}$, and $\phi \sum \mu=0.9 \mathrm{~cm}^{2} / \mathrm{Vs}$ for $\mathrm{MAPbI}_{3}$. While TRMC is known to underestimate mobilites in certain cases, ${ }^{39}$ relative measurements are reasonably unambiguous, and we can conclude that the present $\mathrm{LaYS}_{3}$ films have a sum of mobilities roughly 100 times lower than $\mathrm{MAPbI}_{3}$.

Extracting a single representative lifetime from TRMC transient data is challenging. ${ }^{40}$ Here, the lifetime $\tau$ of the decay is approximated by simply fitting to a single exponential function, and plotted as a function of fluence in Fig. 6(b) for $\mathrm{LaYS}_{3}$ and $\mathrm{MAPbI}_{3}$. The minimum resolvable decay time is limited by the $\mathrm{RC}$ constant of our cavity, and is roughly 

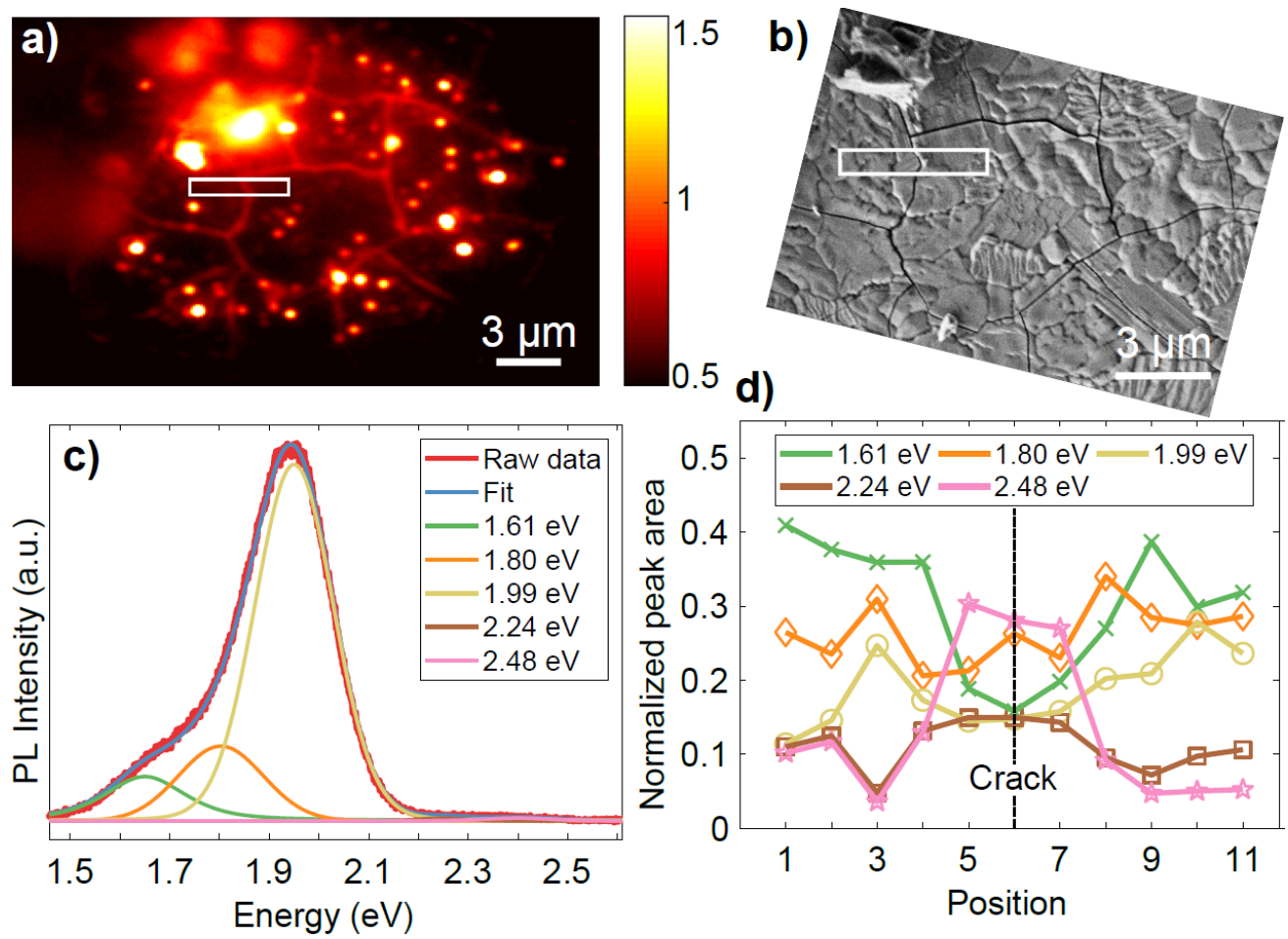

Figure 7: (a): Steady-state PL intensity image (spectrally integrated) of a LaYS 3 film, showing higher PL intensity at the film cracks, as well as in highly localized, sub-micron sized areas ('luminescent centers'). (b): SEM image of the same area, showing no apparent correlation between the localized luminescence centers and film morphology. (c): PL spectrum taken on one of the luminescent centers, showing the five Lorentzian peaks used for fitting the PL spectrum. Notice the negligible contribution of the two higher energy peaks. (d): Relative weight of the same five fitting peaks as a function of position in a PL line scan performed across a crack in the region marked by a white box in (a), from left (position 1) to right (position 11). Position 6 corresponds to the location of the crack. Notice the increasing contribution of the two higher energy peaks as the crack is approached. The actual PL spectra from the line scan are shown in Fig. S16, Supporting Information.

20 ns. At high optical fluence, higher order (bimolecular and Auger) recombination processes will dominate the transient, ${ }^{41}$ while at lower fluence the decay is expected to be dominated by monomolecular processes. ${ }^{34}$ This is manifest as a fluence-dependent value of $\tau$, as observed in Fig. 6(b). In the narrow fluence window that is experimentally available for $\mathrm{LaYS}_{3}$, the extracted lifetimes (up to $30 \mathrm{~ns}$ ) are only marginally lower than those of $\mathrm{MAPbI}_{3}$. Due to the fluence dependence of the carrier lifetimes, the lifetimes of $\mathrm{LaYS}_{3}$ may be even higher at lower fluence.

Indirect indication of potentially long carrier lifetimes in our previous work on $\mathrm{LaYS}_{3}{ }^{6}$ 
based on its strong steady-state PL emission was actually one of the factors motivating the more detailed investigation carried out in the present work. To elucidate possible reasons behind long lifetimes and low mobilities in our $\mathrm{LaYS}_{3}$ films, spatially-resolved PL characterization is performed. A striking feature of the PL image in Fig. 7(a) is the strong spatial inhomogeneity of PL emission intensity. In a basic model of PL in semiconductors, ${ }^{37}$ the emitted photon density is proportional to both the steady-state photogenerated carrier density and the minority carrier lifetime, hence the brighter regions in the PL image can be related to longer lifetimes. When the PL image is compared to a SEM image of the same area (Fig. 7(b)), three regions can be identified in decreasing order of carrier lifetime: (i) highly localized (sub-micron sized) luminescent centers; (ii) film cracks, and (iii) the bulk of the film. The spectral profile of PL is also strongly inhomogeneous in the $\mu \mathrm{m}$ spatial range as demonstrated by a spectrally-resolved PL line scan taken across a crack as indicated by the white rectangle in Fig. 7(a). When each PL spectrum from the line scan is fitted with five Lorentzian peaks as in Fig. 7(c), the relative weight of each peak changes significantly from point to point (Fig. $7(\mathrm{~d})$ ). In particular, the intensity of the lowest-energy peak at $\sim 1.6 \mathrm{eV}$ drops in proximity of a crack, while the intensity of the highest-energy peak at $\sim 2.5 \mathrm{eV}$ (nominally above the band gap of $\mathrm{LaYS}_{3}$ ) increases significantly at the same points. A PL spectrum from one of the small isolated luminescent centers visible in Fig. 7(a) is shown in Fig. 7(c). The PL emission of those luminescent centers is clearly different from the near-crack PL emission. It consists of an intense peak at $1.94 \mathrm{eV}$ with a low-energy shoulder, similar to the large-area PL spectrum of $\mathrm{LaYS}_{3}$ reported in our previous publication. ${ }^{6}$ Interestingly, the location of the luminescent centers does not correspond to specific crystal grains and, in general, cannot be easily correlated to morphological features of the film visible in the SEM image of the PL-imaged area (Fig. 7(b)).

The observation of above-band gap PL at the film cracks, and the presence of a native oxide layer at surfaces due to air exposure (see for example Fig. 2(b)) indicate that oxygen inclusions in the nominally $\mathrm{LaYS}_{3}$ crystal may play a major role in PL emission in our 


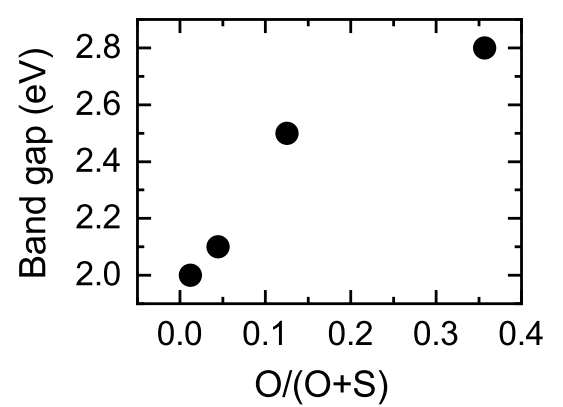

(a)

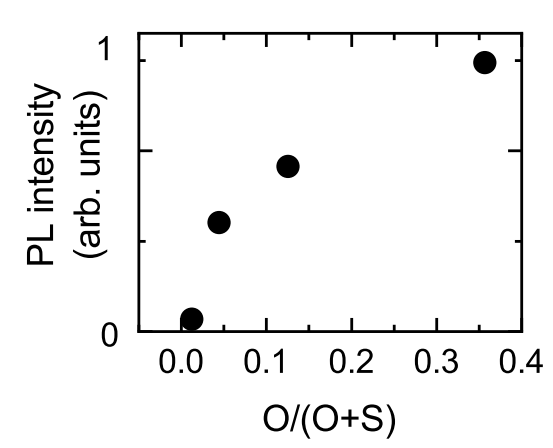

(c)

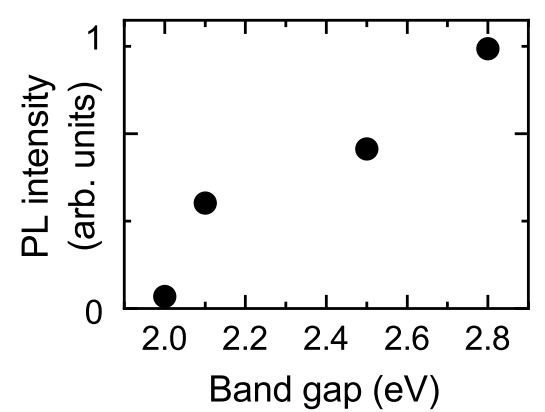

(b)

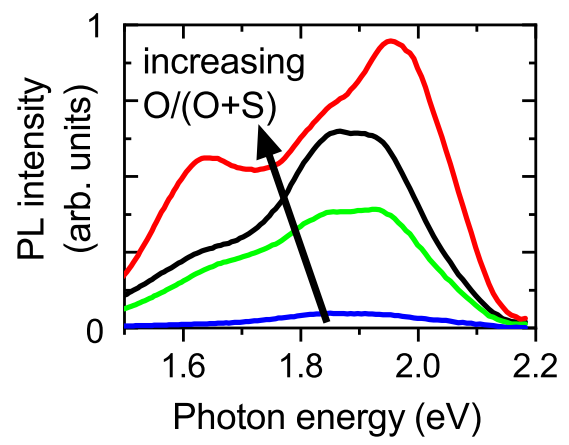

(d)

Figure 8: Correlations between residual oxygen, band gap, and integrated PL intensity in different $\mathrm{LaY}(\mathrm{O}, \mathrm{S})_{3}$ films. (a): Band gap (extracted from Tauc plots) as a function of oxygen content (from EDX). (b): Spectrally integrated, large-area PL intensity $\left(1 \mathrm{~mm}^{2}\right.$ spot) versus band gap. (c): Spectrally-integrated PL intensity versus oxygen content. (d): Actual largearea PL spectra as a function of oxygen content. The spectra belong to four samples with the four oxygen contents shown in (c). The only signal detected above $2.2 \mathrm{eV}$ is a weak reflected laser tail.

films. To qualitatively verify this hypothesis, we produced $\mathrm{LaY}(\mathrm{O}, \mathrm{S})_{3}$ films with different $\mathrm{O} /(\mathrm{O}+\mathrm{S})$ ratios by leaking small amounts of air into the tube furnace during the $1000^{\circ} \mathrm{C}$ sulfurization step of $\mathrm{LaYS}_{3}$. The band gap of $\mathrm{LaY}(\mathrm{O}, \mathrm{S})_{3}$ films increases roughly linearly with the $\mathrm{O} /(\mathrm{O}+\mathrm{S})$ ratio (Fig. 8(a)). A similar trend has been observed in the oxysulfide perovskite $\operatorname{BaZr}(\mathrm{O}, \mathrm{S})_{3}{ }^{24}$ and is common in oxysulfide materials in general. Together with widening of the band gap, an overall increase in large-area PL intensity (Fig. 8(c)) and qualitative changes in the large-area PL spectra (Fig. 8(d)) are observed with increasing substitution of sulfur by oxygen. In particular, the main PL peak blue-shifts and the lowerenergy shoulder increases in intensity with increasing oxygen content in the bulk. While the PL spectra of the small luminescent centers are qualitatively similar to the large-area 
PL spectra of $\mathrm{LaY}(\mathrm{O}, \mathrm{S})_{3}$ films, the PL spectra of the cracks are not (compare Fig. 8(d) and Fig. S16, Supporting Information). In view of this observation, we hypothesize that the luminescent spots consist of isolated $\mathrm{LaY}(\mathrm{O}, \mathrm{S})_{3}$ phases where the oxygen originally present in the $\mathrm{LaYO}_{3}$ precursors is not completely removed by reaction with $\mathrm{H}_{2} \mathrm{~S}$. Those could, therefore, be $\mathrm{LaY}(\mathrm{O}, \mathrm{S})_{3}$ phases formed at high temperature, just like the bulk $\mathrm{LaY}(\mathrm{O}, \mathrm{S})_{3}$ films in Fig. 8. On the other hand, the near-crack regions could be areas where $\mathrm{LaYS}_{3}$ was formed at high temperature but was converted into $\mathrm{LaY}(\mathrm{O}, \mathrm{S})_{3}$ or even $\mathrm{LaYO}_{3}$ upon air exposure. This explanation is plausible since crack formation probably occurs in the cooldown phase. PL emission at cracks and at luminescent centers (the latter labeled "traps" from now on) could then be attributed to two different types of defect levels in LaY $(\mathrm{O}, \mathrm{S})_{3}$, which depend on the growth temperature. Interestingly, yttrium oxysulfide and lanthanum oxysulfide $\left(\mathrm{Y}_{2} \mathrm{O}_{2} \mathrm{~S}\right.$ and $\left.\mathrm{La}_{2} \mathrm{O}_{2} \mathrm{~S}\right)$ are known to be highly luminescent materials, as they were investigated in the 1970s and 1980s as phosphors for cathode ray tubes. ${ }^{42}$

In view of the PL results, the measurement of carrier lifetime and mobility by TRMC must be interpreted with caution, as the lifetime in the bulk might be short enough for recombination to occur within the laser pulse. If that was the case, the mobility would be underestimated, because the peak photo-conductance value would be reduced by bulk recombination within the laser pulse, and the extracted lifetime would be overestimated, because only the (longer) trap lifetime could be distinguished in the TRMC decay. For $\mathrm{MAPbI}_{3}$ absorbers, it is known that traps can strongly influence the mobility extracted by TRMC. ${ }^{43}$ For this reason, we consider the lifetime and mobilities extracted by TRMC as an upper and lower limit to the bulk lifetimes and mobilities, respectively. Still, the values extracted by TRMC may be relevant from a device perspective, since the trap states are so closely spaced (Fig. 7(a)) that a significant fraction of photogenerated carriers might be captured by those states before reaching the contacts. 


\section{Band positions}

According to the Mott-Schottky plots in Fig. 5(c), the flat-band potential of $\mathrm{LaYS}_{3}$ is about $-0.25 \mathrm{~V}$ vs. RHE, which can be translated into a work function of about $4.2 \mathrm{eV}$ versus vacuum. By measuring the work function of $\mathrm{LaYS}_{3}$ with an alternative method (Kelvin probe in air), comparable values in the $4.1-4.3 \mathrm{eV}$ range are obtained depending on the sample. Direct determination of the n-type doping density from electrochemical Mott-Schottky plots is unreliable due to the high series resistance, as explained earlier in the article. Nevertheless, the doping density can be roughly estimated from the measured resistivity and carrier mobilities. With $0.009 \mathrm{~cm}^{2} / \mathrm{Vs}$ being a lower limit to the bulk mobility, an upper limit of $5 \times 10^{14} \mathrm{~cm}^{-3}$ for the n-type doping density is derived. Assuming for example $10^{14} \mathrm{~cm}^{-3}$ doping, the Fermi level position would be $0.30 \mathrm{eV}$ below the conduction band, ${ }^{37}$ thus yielding a rough estimate of $3.9 \mathrm{eV}$ for the electron affinity of $\mathrm{LaYS}_{3}$. With a band gap of $2.0 \mathrm{eV}$, the valence band position would then be $5.9 \mathrm{eV}$ below the vacuum level. Those results are in fair agreement with the $3.7 \mathrm{eV}$ electron affinity estimated with a simple theoretical model based on the electronegativity of the component atoms. ${ }^{44}$

\section{Solar cell prototypes}

While the present $\mathrm{LaYS}_{3}$ films are poorer photovoltaic materials than state-of-the-art $\mathrm{MAPbI}_{3}$ perovksites, especially in terms of carrier mobility and inhomogeneity, our initial measurements seem to indicate that $\mathrm{LaYS}_{3}$ and $\mathrm{MAPbI}_{3}$ may share a few important properties. Both have low native doping density and a similar position of the conduction band position (electron affinity). ${ }^{45}$ For this reason, a single-junction device architecture similar to that of $\mathrm{MAPbI}_{3}$ solar cells appears to be a natural choice for evaluating the potential of $\mathrm{LaYS}_{3}$ as a solar absorber. However, the very high processing temperature of $\mathrm{LaYS}_{3}$ poses a serious challenge to the candidate contact materials and transport layers to be deposited before the absorber. At $1000^{\circ} \mathrm{C}$, most back contact materials diffuse into the absorber, react with $\mathrm{H}_{2} \mathrm{~S}$ to form metal sulfides, or both. While mechanical stacking techniques may ultimately 
be preferable for circumventing this issue ${ }^{46}$ here we attempt growth of $\mathrm{LaYS}_{3}$ directly on refractory metal back contacts. To simplify the problem, we do not include any additional hole- or electron transport layer between the back contact and $\mathrm{LaYS}_{3}$. As potential back contact materials, we test TaN and HOPG due to their high temperature resistance. According to Kelvin probe measurements, the work functions of those metals are $4.7 \mathrm{eV}$, and $4.5 \mathrm{eV}$ respectively. The work functions increase, respectively, to $4.9 \mathrm{eV}$, and $4.7 \mathrm{eV}$ after performing an $\mathrm{O}_{2}$ plasma treatment on the as-grown materials. After $900^{\circ} \mathrm{C}$ sulfurization of LaY on the back contacts, a 100-200 nm-thick TaS ${ }_{2}$ interlayer is observed between $\mathrm{LaYS}_{3}$ and TaN, whereas no interlayers are observed between $\mathrm{LaYS}_{3}$ and HOPG (Fig. 3). $\mathrm{TaS}_{2}$ is a metallic compound (resistivity of $6 \times 10^{-3} \Omega \mathrm{cm}$ ) with a high work function of about $5.2 \mathrm{eV}$ according to Kelvin probe measurements. From the above findings, both TaN and HOPG appear more suitable as hole contact than as electron contacts, so $\mathrm{LaYS}_{3}$ solar cells are designed accordingly with $\mathrm{CdS}$ or $\mathrm{TiO}_{2}$ as electron transport layers on top of $\mathrm{LaYS}_{3}$. Growth of $\mathrm{LaYS}_{3}$ directly on crystalline $\mathrm{Si}$ is also attempted, in order to evaluate its potential applicability in tandem solar cells employing a Si bottom absorber. At sulfurization temperatures above $900^{\circ} \mathrm{C}$, we observe formation of $\mathrm{SiS}$ both on the back side of the $\mathrm{Si}$ wafer, as well as on the side coated with $\mathrm{LaYS}_{3} .900^{\circ} \mathrm{C}$ is therefore an upper limit for the maximum sulfurization temperature on $\mathrm{Si}$, unless a very effective $\mathrm{H}_{2} \mathrm{~S}$ diffusion barrier can be developed.

A few differences are observed for $\mathrm{LaYS}_{3}$ films when grown on TaN and HOPG with respect to the case of a bare quartz substrate. Firstly, adhesion of the $\mathrm{LaYS}_{3}$ after sulfurization is poor when the precursor film is deposited on the as-grown back contacts (Fig. S17, Supporting Information). Secondly, TaN and $\mathrm{LaYS}_{3}$ intermix significantly at sulfurization temperatures above $900^{\circ} \mathrm{C}$, whereas no intermixing between $\mathrm{LaYS}_{3}$ and HOPG is detected even at $1000^{\circ} \mathrm{C}$. Thirdly, $\mathrm{LaYS}_{3}$ on both TaN and HOPG has negligible oxygen content after sulfurization at $900^{\circ} \mathrm{C}$ (Fig. S18, Supporting Information). This is different from the case of $\mathrm{LaYS}_{3}$ on quartz, which has residual oxygen even at higher sulfurization tempera- 


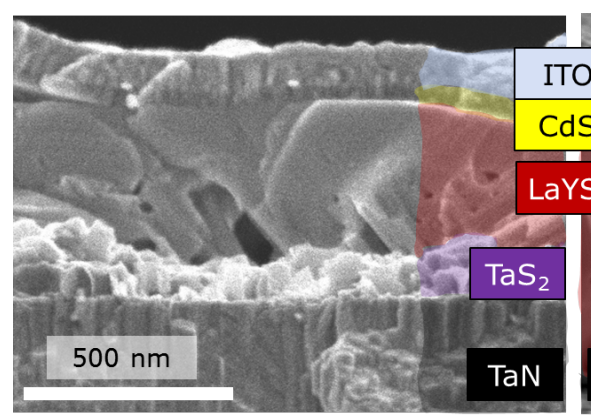

(a)

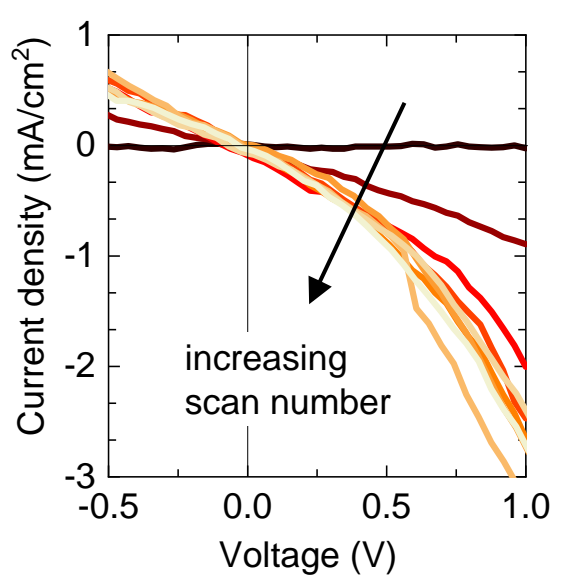

(c)

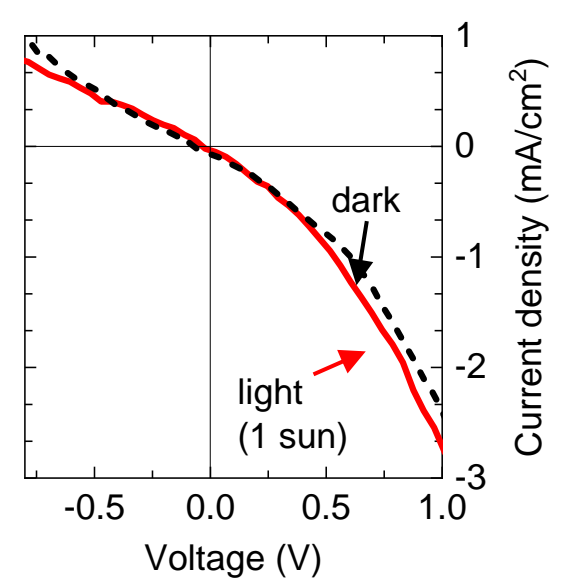

(d)

Figure 9: (a,b): Cross sectional SEM images of two completed $\mathrm{LaYS}_{3}$ solar cells with different back contacts. (a): quartz/TaN/LaYS $/ \mathrm{CdS} /$ ITO. Notice the $\mathrm{TaS}_{2}$ layer formed during the $\mathrm{LaYS}_{3}$ sulfurization step. (b): HOPG/LaYS $/ \mathrm{CdS} / \mathrm{ITO}$. Note that the poor adhesion between $\mathrm{LaYS}_{3}$ and HOPG is due to the sample preparation step for SEM imaging and is not a general feature of $\mathrm{LaYS}_{3}$ on $\mathrm{O}_{2}$ plasma-treated HOPG. (c,d): Current density versus voltage (JV) curves of a $\mathrm{LaYS}_{3}$ solar cell with a TaN back contact. (c): Repeated dark scans on the same cell, showing an initial increase in current with scan number, with a stable JV curve only obtained after a few repeated scans. (d): Dark and illuminated JV curves after stabilization. The cell is illuminated using the AM 1.5 G spectrum at 1 sun intensity.

tures (Fig. 2(a)). Those observations further support the hypothesis that residual oxygen in $\mathrm{LaYS}_{3}$ on quartz originates from reduction of the substrate. Finally, metallic and oxide precursors yield similar morphologies, which are in turn similar to the morphology of $\operatorname{LaYS}_{3}$ on quartz from oxide precursors (Fig. S19, Supporting Information).

In view of the above observations, a few modifications to the $\mathrm{LaYS}_{3}$ growth process are employed when growing it on metallic back contacts instead of on quartz. These are: (i) 
treating the substrates in an $\mathrm{O}_{2}$ plasma to improve adhesion; (ii) limiting the sulfurization temperature to $900^{\circ} \mathrm{C}$ for the case of the TaN back contacts; (iii) employing metallic LaY precursors instead of oxide precursors, as oxide precursors still have poor substrate adhesion in spite of the $\mathrm{O}_{2}$ plasma treatment. Cross sectional SEM images of completed devices featuring both back contact materials are shown in Fig. $9(\mathrm{a}, \mathrm{b})$. Despite the observation of photoconductivity in bare $\mathrm{LaYS}_{3}$ films (Fig. 5(d)) and of some diode-like behavior on completed devices (Fig. 9(c)), no measurable photocurrent is detected in $\mathrm{LaYS}_{3}$ solar cells either on TaN or on HOPG, using either CdS or $\mathrm{TiO}_{2}$ as an electron transport layer (Fig. 9(d)).

\section{Discussion and conclusion}

A wide range of properties of the sulfide perovskite $\mathrm{LaYS}_{3}$ have been experimentally characterized in $\mathrm{LaYS}_{3}$ films grown by sulfurization of $\mathrm{LaY}$ or $\mathrm{LaYO}_{3}$ precursors films in $\mathrm{H}_{2} \mathrm{~S}$. They are summarized in Table 1. The optimal sulfurization temperature appears to be around $1000^{\circ} \mathrm{C}$ for films grown on quartz. Regarding its originally envisioned application as a wide band gap photoabsorber in tandem solar cells and water splitting cells, some encouraging features of $\mathrm{LaYS}_{3}$ have emerged. $\mathrm{LaYS}_{3}$ films are air-stable and large-grained $(>1 \mu \mathrm{m}$ grain diameter), possess an optimal band gap (2.0 eV), exhibit photoconductivity, and have long minority carrier lifetimes (several tens of ns) comparable to those of $\mathrm{MAPbI}_{3}$.

Despite those promising results, a number of issues have also been identified. Most importantly, the high sulfurization temperature necessary to crystallize $\mathrm{LaYS}_{3}$ renders integration with a low-band gap bottom cell challenging. Nevertheless, we attempted to fabricate prototype single-junction solar cells by growing $\mathrm{LaYS}_{3}$ on highly stable back contact materials such as TaN and HOPG. Although no significant intermixing was observed between the $\mathrm{LaYS}_{3}$ absorber and the back contacts, and although some diode-like rectification was observed under forward bias, those cells did not have a measurable photocurrent. Inclusion of a temperature-resistant hole transport layer in the device structure might facilitate future 
development. A second issue identified in this study is the highly inhomogeneous electronic quality of our $\mathrm{LaYS}_{3}$ films, with localized sub-micron regions exhibiting the longest lifetimes (and presumably low mobilities), possibly due to carrier trapping in the defect states of small LaY $(\mathrm{O}, \mathrm{S})_{3}$ phases. Those trap states may explain the very low overall mobility measured in $\mathrm{LaYS}_{3}$ films, as well as their surprisingly long lifetimes. We propose that efficient capture of photogenerated carriers by those traps is a major reason for the lack of photocurrent in the fabricated solar cells. Finally, native doping in $\mathrm{LaYS}_{3}$ appears to be weak (not above the $10^{14} \mathrm{~cm}^{-3}$ range). Combined with the low mobility, this results in a relatively high electrical resistivity. As the absorption coefficient of $\mathrm{LaYS}_{3}$ in the first $0.5 \mathrm{eV}$ above the band gap is rather weak compared to other photovoltaic absorbers, the $\mathrm{LaYS}_{3}$ layer thickness would have to be of several $\mu \mathrm{m}$, thus exacerbating series resistance issues due to the high absorber resistivity.

To address some of those problems, major advances are required in future work. The electronic quality of $\mathrm{LaYS}_{3}$ must be improved by means of an increase in the intrinsic, bulk carrier lifetime of $\mathrm{LaYS}_{3}$ and the elimination of the localized trap states. Fine tuning of the sulfurization process should be the key to achieve this goal. Any improvement in the bulk carrier lifetime will also result in higher excess carrier densities under illumination, which might be enough to achieve a sufficiently low resistivity under illumination without resorting to extrinsic doping. The high temperature necessary for $\mathrm{LaYS}_{3}$ growth, which drastically limits the choice of compatible materials for device fabrication, might be decreased by alkali-assisted growth. ${ }^{47}$ Alternatively, mechanical stacking techniques as opposed to monolithic growth of $\mathrm{LaYS}_{3}$ on a silicon bottom cell might be envisioned for tandem solar cell fabrication. ${ }^{46}$ 
Table 1: List of properties of $\mathrm{LaYS}_{3}$ films that have been measured or calculated in this work. Note that, in many cases, the value given is only a rough estimate (e.g. the relative permittivity) and/or it has been derived from other quantities, with subsequent error propagation (e.g. the experimental electron affinity), and/or it represents a lower- or upper limit (e.g. the carrier lifetime). The error bar is included only in the cases where it is straighforward to determine. For the other quantities, refer to the discussion in the main text for how the measurement was performed.

\begin{tabular}{|c|c|c|c|c|}
\hline & Experiment & & Theory & \\
\hline Property & Result & Technique & Result & Approach \\
\hline Crystal structure & $\begin{array}{l}\text { mainly } \mathrm{CeTmS}_{3} \\
\left(\mathrm{P} 2_{1} / m\right)\end{array}$ & $\mathrm{XRD}$ & $\begin{array}{l}\mathrm{CeTmS}_{3} \\
\left(\mathrm{P} 2_{1} / m\right)\end{array}$ & PSEsol + mBEEF \\
\hline Band gap & $\begin{array}{l}2.0 \pm 0.1 \mathrm{eV} \\
(\text { direct })\end{array}$ & Ellipsometry & $\begin{array}{l}1.79 \pm 0.30 \mathrm{eV} \\
\text { (direct) }\end{array}$ & GLLB-SC \\
\hline Refractive index & $2.5 \pm 0.1$ & Ellipsometry & & \\
\hline Hole + electron mobility & $\geq 0.009 \mathrm{~cm}^{2} / \mathrm{Vs}$ & TRMC & & \\
\hline Minority carrier lifetime & $\leq 30 \mathrm{~ns}$ & TRMC & & \\
\hline Relative permittivity & $\overline{7} \pm 2$ & High-frequency capacitance asymptote & & \\
\hline Resistivity & $\begin{array}{l}1 \times 10^{6} \Omega \mathrm{cm} \\
(2 \pm 1) \times 10^{6} \Omega \mathrm{cm}\end{array}$ & $\begin{array}{l}\text { Solar cell series resistance } \\
\text { Capacitance cutoff frequency }\end{array}$ & & \\
\hline Doping type & $\mathrm{n}$ & Electrochemical Mott-Schottky & & \\
\hline Doping density & $<5 \times 10^{14} \mathrm{~cm}^{-3}$ & (derived) Resistivity + TRMC mobility & & \\
\hline Work function & $\begin{array}{l}4.2 \pm 0.1 \mathrm{eV} \\
4.2 \mathrm{eV}\end{array}$ & $\begin{array}{l}\text { Kelvin probe } \\
\text { Electrochemical Mott-Schottky }\end{array}$ & & \\
\hline Electron affinity & $\leq 3.9 \mathrm{eV}$ & (derived) Work function + doping density & $3.7 \mathrm{eV}$ & mean electronegativity ${ }^{44}$ \\
\hline Electron effective mass & & & $0.49 m_{\mathrm{e}}$ & GLLB-SC \\
\hline Hole effective mass & & & $0.67 m_{\mathrm{e}}$ & GLLB-SC \\
\hline Exciton binding energy & & & $\sim 70 \mathrm{meV}$ & Bohr hydrogen atom ${ }^{37}$ \\
\hline Stability in acid $\left(\mathrm{HNO}_{3}\right)$ & \multicolumn{4}{|c|}{ Immediately etched at $\mathrm{pH}=1$} \\
\hline Stability in base $(\mathrm{NaOH})$ & \multicolumn{4}{|c|}{ No visual changes at $\mathrm{pH}=13$ for 2 hours } \\
\hline
\end{tabular}




\section{Acknowledgements}

The experimental and computational work at SurfCat and CAMD was supported by Grant No. 9455 from VILLUM Fonden. The Center for Nanostructured Graphene is sponsored by the Danish National Research Foundation (Project No. DNRF103). The PL imaging setup has been partly funded by the IDUN Center of Excellence funded by the Danish National Research Foundation (Project No. DNRF122) and VILLUM Fonden (Grant No. 9301).

\section{References}

(1) Jain, A.; Shin, Y.; Persson, K. A. Computational predictions of energy materials using density functional theory. Nat. Rev. Mater. 2016, 1, 15004.

(2) Curtarolo, S.; Hart, G. L. W.; Nardelli, M. B.; Mingo, N.; Sanvito, S.; Levy, O. The high-throughput highway to computational materials design. Nat. Mater. 2013, 12, $191-201$.

(3) Castelli, I. E.; Hüser, F.; Pandey, M.; Li, H.; Thygesen, K. S.; Seger, B.; Jain, A.; Persson, K. A.; Ceder, G.; Jacobsen, K. W. New Light-Harvesting Materials Using Accurate and Efficient Bandgap Calculations. Adv. Energy Mater. 2015, 5, 1400915.

(4) Seger, B.; Castelli, I. E.; Vesborg, P. C. K.; Jacobsen, K. W.; Hansen, O.; Chorkendorff, I. 2-Photon tandem device for water splitting: comparing photocathode first versus photoanode first designs. Energy Environ. Sci. 2014, 7, 2397-2413.

(5) Butler, K. T.; Frost, J. M.; Skelton, J. M.; Svane, K. L.; Walsh, A. Computational materials design of crystalline solids. Chem. Soc. Rev. 2016, 45, 6138-6146.

(6) Kuhar, K.; Crovetto, A.; Pandey, M.; Thygesen, K. S.; Seger, B.; Vesborg, P. C. K.; Hansen, O.; Chorkendorff, I.; Jacobsen, K. W. Sulfide perovskites for solar energy con- 
version applications: computational screening and synthesis of the selected compound LaYS $_{3}$. Energy Environ. Sci. 2017, 10, 2579-2593.

(7) Yoshikawa, K.; Kawasaki, H.; Yoshida, W.; Irie, T.; Konishi, K.; Nakano, K.; Uto, T.; Adachi, D.; Kanematsu, M.; Uzu, H.; Yamamoto, K. Silicon heterojunction solar cell with interdigitated back contacts for a photoconversion efficiency over $26 \%$. Nat. Energy 2017, 2, 17032.

(8) Green, M. A.; Bremner, S. P. Energy conversion approaches and materials for highefficiency photovoltaics. Nat. Mater. 2016, 16, 23-34.

(9) Hanna, M. C.; Nozik, A. J. Solar conversion efficiency of photovoltaic and photoelectrolysis cells with carrier multiplication absorbers. J. Appl. Phys. 2006, 100, 074510.

(10) Seger, B.; Hansen, O.; Vesborg, P. C. K. A Flexible Web-Based Approach to Modeling Tandem Photocatalytic Devices. Solar RRL 2017, 1, e201600013.

(11) Polman, A.; Knight, M.; Garnett, E. C.; Ehrler, B.; Sinke, W. C. Photovoltaic materials: Present efficiencies and future challenges. Science 2016, 352, aad4424.

(12) Ager, J. W.; Shaner, M. R.; Walczak, K. A.; Sharp, I. D.; Ardo, S. Experimental demonstrations of spontaneous, solar-driven photoelectrochemical water splitting. Energy Environ. Sci. 2015, 8, 2811-2824.

(13) Eperon, G. E.; Hörantner, M. T.; Snaith, H. J. Metal halide perovskite tandem and multiple-junction photovoltaics. Nat. Rev. Chem. 2017, 1, 0095.

(14) Bush, K. A.; Manzoor, S.; Frohna, K.; Yu, Z. J.; Raiford, J. A.; Palmstrom, A. F.; Wang, H.-P.; Prasanna, R.; Bent, S. F.; Holman, Z. C.; McGehee, M. D. Minimizing Current and Voltage Losses to Reach 25\% Efficient Monolithic Two-Terminal Perovskite-Silicon Tandem Solar Cells. ACS Energy Lett. 2018, 2173-2180. 
(15) Christians, J. A.; Schulz, P.; Tinkham, J. S.; Schloemer, T. H.; Harvey, S. P.; Tremolet de Villers, B. J.; Sellinger, A.; Berry, J. J.; Luther, J. M. Tailored interfaces of unencapsulated perovskite solar cells for $>1,000$ hour operational stability. Nat. Energy 2018, 3, 68-74.

(16) Jodlowski, A.; Rodríguez-Padrón, D.; Luque, R.; de Miguel, G. Alternative Perovskites for Photovoltaics. Adv. Energy Mater. 2018, 1703120, 1703120.

(17) Yan, L.; Xue, Q.; Liu, M.; Zhu, Z.; Tian, J.; Li, Z.; Chen, Z.; Chen, Z.; Yan, H.; Yip, H.-L.; Cao, Y. Interface Engineering for All-Inorganic CsPbI 2 Br Perovskite Solar Cells with Efficiency over 14\%. Adv. Mater. 2018, 30, 1802509.

(18) Bhalla, A. S.; Guo, R.; Roy, R. The perovskite structure - a review of its role in ceramic science and technology. Materials Research Innovations 2000, 4, 3-26.

(19) Niu, S.; Huyan, H.; Liu, Y.; Yeung, M.; Ye, K.; Blankemeier, L.; Orvis, T.; Sarkar, D.; Singh, D. J.; Kapadia, R.; Ravichandran, J. Bandgap Control via Structural and Chemical Tuning of Transition Metal Perovskite Chalcogenides. Adv. Mater. 2017, 29, 1604733.

(20) Yang, S. Y.; Seidel, J.; Byrnes, S. J.; Shafer, P.; Yang, C.-H.; Rossell, M. D.; Yu, P.; Chu, Y.-H.; Scott, J. F.; Ager, J. W.; Martin, L. W.; Ramesh, R. Above-bandgap voltages from ferroelectric photovoltaic devices. Nat. Nanotechnol. 2010, 5, 143-147.

(21) Sun, Y.-Y.; Agiorgousis, M. L.; Zhang, P.; Zhang, S. Chalcogenide Perovskites for Photovoltaics. Nano Lett. 2015, 15, 581-585.

(22) Ju, M.-G.; Dai, J.; Ma, L.; Zeng, X. C. Perovskite Chalcogenides with Optimal Bandgap and Desired Optical Absorption for Photovoltaic Devices. Adv. Energy Mater. 2017, 2, 1700216 . 
(23) Meng, W.; Saparov, B.; Hong, F.; Wang, J.; Mitzi, D. B.; Yan, Y. Alloying and Defect Control within Chalcogenide Perovskites for Optimized Photovoltaic Application. Chem. Mater. 2016, 28, 821-829.

(24) Perera, S.; Hui, H.; Zhao, C.; Xue, H.; Sun, F.; Deng, C.; Gross, N.; Milleville, C.; Xu, X.; Watson, D. F.; Weinstein, B.; Sun, Y.-Y.; Zhang, S.; Zeng, H. Chalcogenide perovskites - an emerging class of ionic semiconductors. Nano Energy 2016, 22, 129135.

(25) Vovan, T.; Khodadad, P. Chemical and structural study of LL'S ${ }_{3}$ combinations, formed with $\mathrm{L}_{2} \mathrm{~S}_{3}$ and $\mathrm{L}_{2} \mathrm{~S}_{3}$ sulphides of lanthanides and yttrium $(\mathrm{L}=\mathrm{La}, \mathrm{Ce}, \mathrm{Pr}, \mathrm{Nd}$ and L' $=$ lanthanides + Y). Bull. Soc. Chim. Fr. 1971, 1, 3454.

(26) Carré, D.; Flahaut, J.; Khodadad, P.; Laruelle, P.; Rodier, N.; Van Tien, V. Etude comparée des structures cristallines des sulfures contenant deux eléments IIIA (scandium, yttrium et lanthanides). J. Solid State Chem. 1973, 7, 321-336.

(27) Goldschmidt, V. M. Geochemische verteilungsgesetze der Elemente:; Norske Videnskap: Oslo, 1927.

(28) Schubert, M.; Gottschalch, V.; Herzinger, C. M.; Yao, H.; Snyder, P. G.; Woollam, J. A. Optical constants of $\mathrm{Ga}_{x} \mathrm{In}_{1-x} \mathrm{P}$ lattice matched to GaAs. J. Appl. Phys. 1995, r7\%, 3416-3419.

(29) Piller, H. Handbook of Optical Constants of Solids; Elsevier, 1997; pp 571-586.

(30) Löper, P.; Stuckelberger, M.; Niesen, B.; Werner, J.; Filipič, M.; Moon, S.-J.; Yum, J.H.; Topič, M.; De Wolf, S.; Ballif, C. Complex Refractive Index Spectra of $\mathrm{CH}_{3} \mathrm{NH}_{3}$ $\mathrm{PbI}_{3}$ Perovskite Thin Films Determined by Spectroscopic Ellipsometry and Spectrophotometry. J. Phys. Chem. Lett. 2015, 6, 66-71. 
(31) Crovetto, A. Estimating complete band diagrams of non-ideal heterointerfaces by combining ellipsometry and photoemission spectroscopy. J. Appl. Phys. 2018, 124, 085302.

(32) Brandt, R. E.; Stevanović, V.; Ginley, D. S.; Buonassisi, T. Identifying defect-tolerant semiconductors with high minority-carrier lifetimes: beyond hybrid lead halide perovskites. MRS Commun. 2015, 5, 265-275.

(33) Li, P.; Anderson, R.; Plovnick, R. Dielectric constant of $\mathrm{CuInSe}_{2}$ by capacitance measurements. J. Phys. Chem. Solids 1979, 40, 333-334.

(34) Labram, J. G.; Chabinyc, M. L. Recombination at high carrier density in methylammonium lead iodide studied using time-resolved microwave conductivity. J. Appl. Phys. 2017, 122, 065501.

(35) Oga, H.; Saeki, A.; Ogomi, Y.; Hayase, S.; Seki, S. Improved Understanding of the Electronic and Energetic Landscapes of Perovskite Solar Cells: High Local Charge Carrier Mobility, Reduced Recombination, and Extremely Shallow Traps. J. Am. Chem. Soc. 2014, 136, 13818-13825.

(36) Savenije, T. J.; Ferguson, A. J.; Kopidakis, N.; Rumbles, G. Revealing the Dynamics of Charge Carriers in Polymer:Fullerene Blends Using Photoinduced Time-Resolved Microwave Conductivity. J. Phys. Chem. C 2013, 117, 24085-24103.

(37) Würfel, P.; Würfel, U. Physics of solar cells, 3rd ed.; Wiley-VCH Verlag GmbH \& Co. KGaA: Wenheim, 2010.

(38) Saeki, A.; Tsuji, M.; Seki, S. Direct Evaluation of Intrinsic Optoelectronic Performance of Organic Photovoltaic Cells with Minimizing Impurity and Degradation Effects. Adv. Energy Mater. 2011, 1, 661-669.

(39) Reid, O. G.; Moore, D. T.; Li, Z.; Zhao, D.; Yan, Y.; Zhu, K.; Rumbles, G. Quantitative 
analysis of time-resolved microwave conductivity data. J. Phys. D: Appl. Phys. 2017, 50, 493002 .

(40) Labram, J. G.; Venkatesan, N. R.; Takacs, C. J.; Evans, H. A.; Perry, E. E.; Wudl, F.; Chabinyc, M. L. Charge transport in a two-dimensional hybrid metal halide thiocyanate compound. J. Mater. Chem. C 2017, 5, 5930-5938.

(41) Labram, J. G.; Perry, E. E.; Venkatesan, N. R.; Chabinyc, M. L. Steady-state microwave conductivity reveals mobility-lifetime product in methylammonium lead iodide. Appl. Phys. Lett. 2018, 113, 153902.

(42) Sella, C.; Martin, J.; Charreire, Y. R.F.-sputtered luminescent rare earth and yttrium oxysulphide films. Thin Solid Films 1982, 90, 181-185.

(43) Reid, O. G.; Yang, M.; Kopidakis, N.; Zhu, K.; Rumbles, G. Grain-Size-Limited Mobility in Methylammonium Lead Iodide Perovskite Thin Films. ACS Energy Lett. 2016, $1,561-565$.

(44) Butler, M. A.; Ginley, D. S. Prediction of Flatband Potentials at SemiconductorElectrolyte Interfaces from Atomic Electronegativities. J. Electrochem. Soc. 1978, 125, 228.

(45) Green, M. A.; Ho-Baillie, A.; Snaith, H. J. The emergence of perovskite solar cells. Nat. Photonics 2014, 8, 506-514.

(46) Essig, S.; Allebé, C.; Remo, T.; Geisz, J. F.; Steiner, M. A.; Horowitz, K.; Barraud, L.; Ward, J. S.; Schnabel, M.; Descoeudres, A.; Young, D. L.; Woodhouse, M.; Despeisse, M.; Ballif, C.; Tamboli, A. Raising the one-sun conversion efficiency of III-V/Si solar cells to $32.8 \%$ for two junctions and $35.9 \%$ for three junctions. Nat. Energy $\mathbf{2 0 1 7}$, 2, 17144 . 
(47) Gershon, T.; Shin, B.; Bojarczuk, N.; Hopstaken, M.; Mitzi, D. B.; Guha, S. The Role of Sodium as a Surfactant and Suppressor of Non-Radiative Recombination at Internal Surfaces in $\mathrm{Cu}_{2} \mathrm{ZnSnS}_{4}$. Adv. Energy Mater. 2014, 5, 1400849. 